\title{
RESPONSE OF NORMALLY CONSOLIDATED KAOLIN CLAY UNDER IRREGULAR CYCLIC LOADING AND COMPARISON WITH PREDICTIONS FROM THE ACCUMULATION PROCEDURE
}

Author 1

- Dimitra Zografou, PhD candidate

- Centre for Offshore Foundation Systems, The University of Western Australia.

Author 2

- Susan Gourvenec, Professor

- Faculty of Engineering and the Environment, University of Southampton, UK. Formerly of the Centre for Offshore Foundation Systems, The University of Western Australia

Author 3

- Conleth O’Loughlin, Associate Professor

- Centre for Offshore Foundation Systems, The University of Western Australia

Full contact details of corresponding author:

- Email: dimitra.zografou@research.uwa.edu.au

- Address: Centre for Offshore Foundation Systems

The University of Western Australia (M053)

35 Stirling Highway

CRAWLEY WA 6009

Australia 


\section{Abstract}

The accumulation procedure on contour diagrams of shear strain is used in geotechnical design to account for the effect of cyclic loading on offshore foundations. In this paper, contour diagrams of maximum shear strain are presented based on a series of stress-controlled, symmetrical and non-symmetrical, cyclic direct simple shear tests on normally consolidated kaolin clay that can be used to re-examine the extensive database of model testing in kaolin clay. It is shown that the failure under non-symmetrical cyclic loading can be defined at a higher maximum shear strain than under symmetrical loading, offering potential opportunities for reducing foundation sizes for structures that are less sensitive to displacement. Staged tests with parcels of uniform amplitudes have been also performed to compare the measured shear strains with the values predicted by the accumulation procedure. It is shown that the accumulation procedure predicts the strain measured in the symmetrical staged tests well but overpredicts shear strains measured in the non-symmetrical staged tests.

\section{Keywords}

Cyclic loading; normally consolidated clay; direct simple shear test

\section{List of notation}
a fitting parameter for contour diagram of $\gamma_{\max }$
b fitting parameter for contour diagram of $\gamma_{\max }$
c fitting parameter for contour diagram of $\gamma_{\max }$
CSR cyclic stress ratio
DSS direct simple shear
$\mathrm{e}_{0} \quad$ void ratio (as extruded)
f frequency
$\mathrm{G}_{\mathrm{cyc}} \quad$ cyclic shear modulus
$\mathrm{G}_{\mathrm{s}} \quad$ specific gravity 
LL liquid limit

$\mathrm{N} \quad$ number of cycles

$\mathrm{N}_{\mathrm{eq}} \quad$ equivalent number of cycles

PL plastic limit

$\mathrm{R}^{2} \quad$ coefficient of determination

$\mathrm{S}_{\mathrm{u}} \quad$ monotonic (DSS) shear strength

$\gamma \quad$ shear strain

$\gamma_{\text {ave }} \quad$ average shear strain

$\gamma_{\text {сус }} \quad$ cyclic shear strain

$\gamma_{\max } \quad$ maximum shear strain

$\Delta \gamma \quad$ change in shear strain

$\Delta \gamma_{\max } / \Delta \mathrm{N}$ Change in maximum shear strain per cycle

$\Delta \sigma^{\prime}{ }_{\mathrm{v}} \quad$ change in vertical effective stress

$\kappa \quad$ slope of swelling line

$\lambda \quad$ slope of normal consolidation line

M critical state friction constant

$\sigma_{\mathrm{v}}^{\prime} \quad$ vertical effective stress

$\sigma_{\mathrm{v} 0}^{\prime} \quad$ initial vertical effective stress

$\tau \quad$ shear stress

$\tau_{\text {ave }} \quad$ average shear stress

$\tau_{\text {сус }} \quad$ cyclic shear stress

$\tau_{\max } \quad$ maximum shear stress

$\tau_{\text {max,f }} \quad$ cyclic shear strength 


\section{Introduction}

The cyclic response of normally consolidated clay is particularly relevant to foundation design of offshore structures, which are subjected to cyclic loading induced by environmental factors and potentially interaction with other seabed infrastructure during operation. Geotechnical foundation design conventionally discounts the shear strength of the seabed to account for the effect of cyclic loading through an accumulation procedure using contour diagrams of shear strain or excess pore pressure derived from programs of advanced laboratory testing (e.g. Andersen 1976, Andersen 2015). The accumulation procedure has been developed and verified for the foundation design of gravity-based fixed platforms that are subjected to waves and wind of high amplitude and frequency (Andersen et al. 1989),but is now also used for the foundation design of a range of offshore structures (Andersen et al. 1993, Andersen et al. 2013), including anchors and subsea structures that are subjected to different cyclic loading regimes to fixed platforms.

One of the main motivations of the present study is to present contour diagrams of shear strain, based on a series of symmetrical and non-symmetrical stress-controlled cyclic direct simple shear (DSS) tests performed on soft normally consolidated kaolin. The dataset of contour diagrams developed in this study provides a useful tool for the interpretation of model test data, as kaolin is a material used extensively for research and a large existing dataset of physical modelling results involving cyclic loading on kaolin is available in the public domain (e.g. Clukey et al. 1995, Chen \& Randolph 2007, Acosta-Martinez \& Gourvenec 2008, Zografou et al. 2018).

DSS tests were chosen in this study as this type of tests is generally preferred in offshore geotechnical site investigation due to the efficiency of sample size and as shear strength from monotonic DSS tests, or simple shear tests, is considered approximately equal to the average soil strength in triaxial compression and extension (Mayne 1985, Randolph 2012) and therefore 
applicable to a range of stress paths encountered beneath a shallow foundation. It is noted that DSS tests (Bjerrum \& Landva 1966) and simple shear tests (Joer et al. 2011, Carraro 2017) are distinguished based on the boundary conditions on the specimen. Stress-controlled tests were chosen, rather than strain-controlled tests, as representative for offshore foundations subjected to cyclic loading. Several studies have been published on stress-controlled cyclic triaxial tests on kaolin (e.g. Meimon \& Hicher 1980, Ho 2013) and strain-controlled cyclic simple shear tests (e.g. Ohara \& Matsuda 1988, Hsu \& Vucetic 2006) but only limited data are available from stress-controlled cyclic DSS tests on normally consolidated kaolin clay (Ansal \& Erken 1989, Zografou et al. 2016). It is noted that the most extensive database of contour diagrams available in the public domain is developed from cyclic element tests on Drammen clay (Andersen 2009). Zografou et al. (2016) observed that contours from cyclic DSS tests on normally consolidated Drammen clay plot above those from cyclic DSS tests on normally consolidated kaolin clay, such that the Drammen clay contour diagrams cannot be used to predict the cyclic response of kaolin clay.

Two types of contour diagrams are presented, derived from the series of DSS tests carried out for this study; (1) based on symmetrical tests, i.e. with average shear stress, $\tau_{\text {ave, equal to zero, }}$ and (2) non-symmetrical tests with cyclic shear stress, $\tau_{\mathrm{cyc}}$, equal to the average shear stress, i.e. $\tau_{\mathrm{ave}}=\tau_{\mathrm{cyc}}$. The components of shear stress, $\tau$, in a cyclic DSS test, i.e. $\tau_{\mathrm{ave}}$ and $\tau_{\text {cyc }}$ and the maximum shear stress in a cycle, $\tau_{\max }$, are illustrated in Figure 1 (a). It is noted that in real conditions, $\tau_{\text {cyc }}$ is induced by cyclic loading while $\tau_{\text {ave }}$ may be induced by the weight of structures and average environmental, installation and operational loads. The two types of contour diagrams presented in the paper represent idealised design load cases that can bound a range of cyclic load conditions relevant to foundations of gravity-based structures, skirted foundations (Watson 1999, Watson \& Randolph 2006), suction anchors/suction caissons (Randolph 1998, Chen \& Randolph 2007), piles and monopiles (Jardine et al. 2012). The 
components of induced shear strain, $\gamma$, are also illustrated in Figure 1 (b), notably the average shear strain, $\gamma_{\text {ave, }}$ cyclic shear strain, $\gamma_{\text {cyc }}$, and maximum shear strain, $\gamma_{\text {max }}$.

The predicted response from the accumulation procedure is compared with observations from staged symmetrical and non-symmetrical $\left(\tau_{\text {ave }}=\tau_{\text {cyc }}\right.$ ) cyclic DSS tests with parcels of uniform amplitude in ascending and/or descending order, conducted as an approximation of irregular cyclic loading in the field. Comparison of the accumulation procedure against staged symmetrical DSS tests (not in kaolin) based on element tests are reported in the literature (Dyvik et al. 1981, Boukpeti et al. 2014), but to the authors' knowledge no comparison has been made with non-symmetrical tests. In the present study, the response of non-symmetrical DSS tests with $\tau_{\mathrm{ave}}=\tau_{\mathrm{cyc}}$ and $\tau_{\mathrm{ave}}>\tau_{\mathrm{cyc}}$, is also compared with the response predicted by the accumulation procedure with strain contour diagrams.

\section{Shear strain accumulation procedure}

Offshore foundations experience irregular cyclic loading of varying amplitude and frequency. The accumulation procedure requires this irregular cyclic loading sequence to be translated into parcels of uniform amplitude shear stresses in ascending order. The process of translating the cyclic loads into cyclic shear stresses is based on the assumption that the ratio of the applied cyclic load to the maximum cyclic load is proportional to the ratio of the shear stress to the monotonic shear strength, $s_{\mathrm{u}}$, or the vertical effective stress, $\sigma^{\prime}{ }_{\mathrm{v}}$. An example translation of an irregular cyclic load sequence into a regular cyclic shear stress sequence, as a function of the number of cycles, $\mathrm{N}$, is provided in Figure 2 (a). The cyclic load sequence is typical of that imparted by a storm, with increasing load magnitude as the storm intensifies followed by decreasing load magnitude as the storm abates.

The accumulation procedure can be performed on contour diagrams of excess pore pressure, average shear strain or cyclic shear strain against $\mathrm{N}$, to define the equivalent number of cycles 
of the maximum load in the irregular cyclic load sequence, $\mathrm{N}_{\mathrm{eq}}$, that causes the same degradation as the irregular cyclic load sequence. The shear strain accumulation procedure is preferred for clays while the pore pressure accumulation is preferred for sands as more accurate measurements of pore pressure can be achieved in sands. Figure 2 (b) shows an example application of the shear strain accumulation procedure on a contour diagram of maximum shear strain, $\gamma_{\max }$, as a function of $\tau_{\max } / \mathrm{s}_{\mathrm{u}}$ and $\mathrm{N}$. As this paper considers both symmetrical and nonsymmetrical cyclic loading, the contour diagrams for both symmetrical and non-symmetrical cyclic loading are presented using $\tau_{\max }$ and $\gamma_{\max }$, rather than $\tau_{\text {сyc }}$ and $\gamma_{\text {cyc }}$ as generally used for symmetrical tests. The accumulation procedure starts with the first parcel, for which $\tau_{\max } / \mathrm{s}_{\mathrm{u}}=$ 0.33 and $\mathrm{N}=150$, such that the starting point on the contour diagram (Figure 2 (b)) is point $\mathrm{A}$, with $\tau_{\max } / \mathrm{s}_{\mathrm{u}}=0.33$ and $\mathrm{N}=1$. This stress level is maintained for 150 cycles, such that the path is horizontal from point $A$ to point $B$ at $N=150$, where it intersects the contour of $\gamma_{\max }=1 \%$. Based on the assumption that the shear strain at the end of a parcel is the same as that at the beginning of the subsequent parcel, this $1 \%$ contour is followed until reaching the stress level of the subsequent parcel, which is at point $\mathrm{C}$ with $\tau_{\max } / \mathrm{s}_{\mathrm{u}}=0.42$ and $\mathrm{N}=5$. The application of the stress increment, from $\tau_{\mathrm{max}} / \mathrm{s}_{\mathrm{u}}=0.33$ to 0.42 , induces an additional change in shear strain, $\Delta \gamma$, which is approximated from the shear-strain response at $\mathrm{N}=1$. Figure 2 (c) shows that the stress increment from $\tau_{\max } / \mathrm{s}_{\mathrm{u}}=0.33$ to $0.42(\tau=4.3$ to $5.5 \mathrm{kPa})$ causes an increase in shear strain, $\Delta \gamma=0.3 \%$. Therefore, on the contour diagram on Figure 2 (b), $\gamma_{\max }$ increases from $1.0 \%$ to $1.3 \%$ (from point $\mathrm{C}$ to point $\mathrm{D}$ ) at $\mathrm{N}=5$. The path is then horizontal to the right for the 35 cycles in the second parcel to reach point $\mathrm{E}$, which lies on the $\gamma_{\max }=2 \%$ contour at $\mathrm{N}=5+35$ $=40$. This process is followed for each parcel, reaching the maximum shear stress level, $\tau_{\max } / \mathrm{s}_{\mathrm{u}}$ $=0.60$, which occurs at $\mathrm{N}=9$ (point $\mathrm{Z}$ ). Hence, the irregular cyclic stress sequence can be represented by a uniform stress sequence of $\tau_{\max } / \mathrm{s}_{\mathrm{u}}=0.60$ with $\mathrm{N}_{\mathrm{eq}}=9$. 
The accumulation procedure is repeated for increasing scaling factors that correlate cyclic load to cyclic shear stress resulting in different values of $\mathrm{N}_{\text {eq }}$ until the failure envelope (i.e. the contour with the highest $\gamma_{\max }$ value) is reached. The shear stress level where the failure envelope is reached is defined as the cyclic shear strength, $\tau_{\mathrm{max}, \mathrm{f} .}$ In the example in Figure 2 (b), the accumulation procedure resulted in the highest $\gamma_{\max }(=5 \%)$, such that the cyclic shear strength is equal to $\tau_{\max , \mathrm{f}} / \mathrm{s}_{\mathrm{u}}=0.60$.

\section{Experimental details}

\subsection{Direct simple shear apparatus}

A total of 22 direct simple shear (DSS) tests were performed at the University of Western Australia using the Geocomp ShearTrac-II DSS apparatus (Geocomp Corporation 2012). DSS tests comprise an initial stage of one-dimensional consolidation followed by a shearing stage during which no volume change is allowed. In the Geocomp apparatus, a zero lateral strain boundary condition is imposed using a stack of rings that surround the specimen. The height of the specimen is kept constant during the shearing stage by active height control (ASTM D6528-07). DSS tests are equivalent to undrained tests as the change in vertical effective stress, $\Delta \sigma_{\mathrm{v}}^{\prime}$, required to maintain the specimen height constant is assumed to equal the change in pore pressure (Bjerrum \& Landva 1966, Dyvik et al. 1987).

The experimental arrangement is shown on Figure 3. The arrangement adopted for this program of testing was modified from the standard arrangement by replacing the stainless steel top cap and the attached rod with polycarbonate replicas, such that the seating pressure was reduced from $3.0 \mathrm{kPa}$ to $0.5 \mathrm{kPa}$. This modification was necessary to minimise disturbance of the soft specimens during preparation. Vertical displacements of the specimen due to the $0.5 \mathrm{kPa}$ seating pressure and assembling the apparatus components above the specimen were monitored before the consolidation stage. This displacement was accounted for in the calculation of the 
final specimen height. The apparatus deformation and lateral confinement of the system were calibrated. The vertical displacements and shear stresses presented in this paper have been corrected based on these calibrations in agreement with ASTM D6528-07.

\subsection{Specimen preparation and installation in the apparatus}

Kaolin, with properties as listed in Table 1, was prepared as a slurry with a water content equal to twice the liquid limit in agreement with Head (1998) for specimen preparation from slurry, and mixed under vacuum for a period of 24 hours before being transferred to a $72 \mathrm{~mm}$ diameter tube where it was consolidated in increments to a maximum vertical stress of $60 \mathrm{kPa}$. The increments were applied for 24 hours and the final increment was applied for at least 48 hours. Specimens were extruded from the tubes of consolidated kaolin into a $71 \mathrm{~mm}$ diameter ring and after trimming excess clay from around the ring, the specimens were pressed out of the ring and into the shearing box, taking care to minimise disturbance. The top cap, rubber membrane and Teflon coated stacked rings were placed around the specimen, which was then positioned in the carriage box of the apparatus. A linear displacement sensor was placed on top of a platen on the top cap to monitor vertical displacements while setting up the apparatus; this sensor was removed after the consolidation stage. After assembling the rod, vertical load cell and second linear vertical displacement sensor, the specimen was submerged in a water bath.

\subsection{Testing procedure}

The specimens were consolidated in the DSS apparatus incrementally to the initial vertical effective stress, $\sigma_{\mathrm{v} 0}^{\prime}$, equal to $70 \mathrm{kPa}$ in agreement with the procedure set out in ASTM D652807. This stress level was chosen to target the minimum strength that is practical for specimen preparation and is representative of soil strengths relevant to subsea foundation systems in soft clay. Each stress increment was maintained for either 1 or 2 hours, with the exception of the final stress increment which was maintained for a minimum of 15 hours in agreement with ASTM D6528-07. 
Monotonic tests were performed under displacement control at a rate of $0.1 \mathrm{~mm} / \mathrm{min}$ to assess the monotonic DSS strength, $\mathrm{s}_{\mathrm{u}}$, of the normally consolidated kaolin. The shear stresses in the cyclic tests were applied as a percentage of this reference DSS strength. Monotonic tests at displacement rates of $1.0 \mathrm{~mm} / \mathrm{min}$ and $2.5 \mathrm{~mm} / \mathrm{min}$ were also performed to capture the stressstrain response at strain rates closer to those in the stress-controlled cyclic tests.

Cyclic DSS tests were performed under stress control using sinusoidal waves with a frequency, $\mathrm{f}=0.1 \mathrm{~Hz}$, typical of a wave during a storm (e.g. Andersen et al. 1988, Mohr et al. 2013), for up to $\mathrm{N}=1500$ cycles, unless failure was reached earlier. Symmetrical and non-symmetrical tests were performed. Before applying the cycles in the non-symmetrical tests, an average shear stress, $\tau_{\text {ave, }}$ was applied at a rate of $10.1 \mathrm{kPa} / \mathrm{min}$. The targeted $\tau_{\text {ave }}$ was maintained until horizontal displacements stabilised (typically up to 30 minutes) during which time the specimen height was kept constant. The sinusoidal cyclic shear stresses, $\tau_{\mathrm{cyc}}$, were then applied about this same $\tau_{\text {ave; }}$; in symmetrical tests the initial stage of loading to $\tau_{\text {ave }}$ was not required as $\tau_{\mathrm{ave}}=0$. The cyclic shear stress rate was not controlled directly. Rather this was a result of the control system, which utilised a proportional-integral-derivative (PID) control loop to vary the displacement rate such that the targeted time history of shear stress was achieved. The PID controller requires as input the cyclic frequency and the magnitude of the cyclic shear stress,

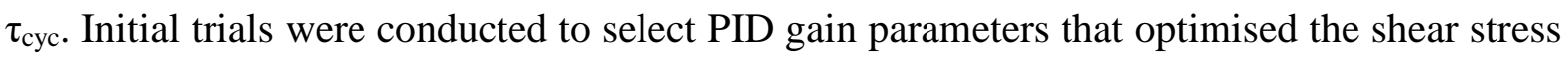
control quality.

Non-symmetrical tests were performed at different cyclic stress ratios (CSR), where CSR is defined as:

$$
\operatorname{CSR}=\frac{\tau_{c y c}}{\tau_{\text {ave }}}
$$

Tests of single uniform amplitude sequences and staged tests with parcels of uniform amplitudes were performed under symmetrical $(\mathrm{CSR}=\infty)$ and non-symmetrical cyclic loading 
conditions with CSR $=1$. The cyclic stresses in the uniform cyclic tests - symmetrical and nonsymmetrical with CSR $=1$ - were selected such that there would be sufficient data to fit strain contours in the respective contour diagrams. Non-symmetrical tests with uniform amplitudes and $\tau_{\text {ave }}>\tau_{\text {cyc }}$ were also conducted, and in particular with CSR $=0.26$ and 0.42 , with shear stresses representative of the loading conditions of a subsea zero-radius bend trigger during pipe-laying (Peek \& Kristiansen 2009, Zografou et al. 2018). The cyclic shear stresses in the staged tests, with the exception of one test [StCs1], were chosen so that failure would not occur in any of the parcels, allowing the effect of cyclic stress history to be investigated.

\subsection{Testing programme}

A detailed overview of the test programme is provided in Table 2. Symmetrical cyclic tests [Cs1 to Cs5] and non-symmetrical cyclic tests with CSR $=1$ [Cns1 to Cns6] were performed to produce contour diagrams for symmetrical and non-symmetrical cyclic loading. Nonsymmetrical tests with CSR $<1$ were also performed [Cns7 and Cns8]. Staged symmetrical tests [StCs1 to StCs4] and non-symmetrical tests [StCns1 and StCns2] were performed to provide a means of assessing the shear strain predicted by the accumulation procedure.

\section{Results}

The results from the cyclic DSS tests are presented in the following sections. It is noted that the void ratio, $\mathrm{e}_{0}$, of the specimens, as extruded, was typically in the range $1.28-1.35$, and it is therefore reasonable to make direct comparisons between the test results. 


\subsection{Symmetrical cyclic tests}

\subsubsection{Definition of failure in symmetrical cyclic DSS tests}

Five symmetrical cyclic DSS tests were performed with uniform cyclic amplitudes. Typical results from a symmetrical cyclic DSS test performed at $\tau_{\mathrm{max}} / \mathrm{s}_{\mathrm{u}}=\tau_{\mathrm{cyc}} / \mathrm{s}_{\mathrm{u}}=0.41$ [Cs3] are presented in Figure 4.

Figure 4 (b) and (c) show that for this example test, shear strain initially develops with a constant change in maximum shear strain per cycle, $\Delta \gamma_{\max } / \Delta \mathrm{N}$, that is approximately equal to 0.02, and that $\Delta \gamma_{\max } / \Delta \mathrm{N}$ increases rapidly from $\mathrm{N}=229$. Figure 4 (d) presents the ratio of the change in vertical effective stress to the initial vertical effective stress, $\Delta \sigma_{\mathrm{v}}^{\prime} / \sigma^{\prime}{ }_{\mathrm{v} 0}$, and shows that $\sigma_{\mathrm{v}}^{\prime}$ decreases as the test progresses. Figure 4 (e) shows the shear stress-shear strain response at $N=1,10,100$ and at failure $(N=229)$, together with the cyclic shear modulus, $G_{c y c}=\tau_{c y c} / \gamma_{c y c}$, as a measure of shear stiffness. $G_{c y c}$ decreases as the test progresses, from $G_{c y c}=696 \mathrm{kPa}$ at $\mathrm{N}=1$ to $\mathrm{G}_{\mathrm{cyc}}=108 \mathrm{kPa}$ at $\mathrm{N}=229$. Failure is therefore observed in the form of cyclic stiffness degradation and is defined here at the point where the change of maximum shear strain per cycle, $\Delta \gamma_{\max } / \Delta \mathrm{N}$, increases markedly. In this particular test, failure is observed at $\mathrm{N}=229$, at which point $\gamma_{\max } \approx 5 \%$ and $\sigma_{\mathrm{v}}^{\prime}$ and $\mathrm{G}_{\mathrm{cyc}}$ have reduced by $69 \%$ and $84 \%$ respectively. Failure in symmetrical cyclic DSS tests [Cs2 to Cs5], as defined above, was observed at a similar value of $\gamma_{\max } \approx 5 \%$.

\subsubsection{Shear stress-shear strain response at $\mathbf{N}=1$ in symmetrical cyclic DSS tests}

Figure 5 presents the shear stress-shear strain response measured in monotonic tests conducted at displacement rates of $0.1 \mathrm{~mm} / \mathrm{min}, 1 \mathrm{~mm} / \mathrm{min}$ and $2.5 \mathrm{~mm} / \mathrm{min}$ [M1, M2 and M3]. The shear stress is normalised by $\mathrm{s}_{\mathrm{u}}$, which was selected from the results from the test performed at 0.1 $\mathrm{mm} / \mathrm{min}$ (the slowest rate considered) at a shear strain $\gamma=15 \%$; the selected shear strain level is in agreement with that of other studies using monotonic strain-controlled DSS tests on 
normally consolidated clay with no clear peak in the shear-strain response (e.g. Andersen et al. 2005, Lunne \& Andersen 2007). Also shown is the response from the first quarter cycle of three cyclic symmetrical tests with $\tau_{\mathrm{cyc}} / \mathrm{s}_{\mathrm{u}}=0.22,0.41$ and 0.65 [StCs1, Cs3 and Cs5] measured from $\tau=0$ to $\tau=\tau_{\max }$, with average displacement rates of $1.0,1.9$ and $6.7 \mathrm{~mm} / \mathrm{min}$ for tests StCs1, Cs3 and Cs5 respectively. The cyclic stress-strain responses are in good agreement with the response in the monotonic tests performed at similar displacement rates, i.e. tests M2 and M3. Therefore the points of the contours on the contour diagrams at $\mathrm{N}=1$ from symmetrical cyclic tests can be derived from the fast monotonic tests at $\gamma=15 \%$, consistent with observations by Idriss \& Dobry (1978).

The results from the mononotonic tests on Figure 5 are consistent with the well-known effect of shear strain rate on undrained shear strength. This effect is attributed to the viscosity of the clay and typically contributes to a 5 to $20 \%$ increase in undrained shear strength for every log

cycle increase in shear strain rate (e.g. Casagrande \& Wilson 1951; Graham et al. 1983, Vaid \& Campanella 1977, Lefebvre \& LeBoeuf 1987, Sheahan et al. 1996, Lunne \& Andersen 2007). The effect of strain rate in the monotonic tests on Figure 5 is most readily assessed by comparing the tests at $0.1 \mathrm{~mm} / \mathrm{min}$ [M1] and $1 \mathrm{~mm} / \mathrm{min}$ [M2]. Shear stresses in test M2 are typically $13 \%$ higher throughout. The implication of this with respect to the application of the accumulation procedure is that the $\tau / \mathrm{s}_{\mathrm{u}}$ ratios used as input to the cyclic tests may appear slightly higher than relative to the shear strength mobilised at a higher rate during cyclic shearing.

\subsubsection{Contour diagrams from symmetrical cyclic DSS tests}

The results of the symmetrical cyclic DSS tests have been used to produce contour diagrams, shown as contours of $\gamma_{\max }$ in $\tau_{\max } / \mathrm{s}_{\mathrm{u}}-\mathrm{N}$ space. It is reiterated that the position of the contours depends on the value of monotonic strength used for normalising the applied shear stresses and 
therefore on the reference strain rate used in the monotonic tests. The contours have been produced based on eight symmetrical cyclic DSS tests (including the first stage of three staged tests) by fitting data points with the same level of $\gamma_{\max }$. Data points at $\mathrm{N}=1$ and for $\tau_{\max } / \mathrm{s}_{\mathrm{u}}>$ 0.65 have been taken from the monotonic test performed at $2.5 \mathrm{~mm} / \mathrm{min}$ as discussed above. Figure 6 shows the contour diagram established from the results of the symmetrical cyclic DSS tests. For this symmetrical cyclic loading case, $\tau_{\max }=\tau_{\text {cyc }}$ (as $\tau_{\mathrm{ave}}=0$ ), but to facilitate comparison with the contour diagram for the non-symmetrical cyclic tests the normalised shear stress ratio on the contour diagram is expressed as $\tau_{\max } / \mathrm{s}_{\mathrm{u}}$ rather than $\tau_{\mathrm{cyc}} / \mathrm{s}_{\mathrm{u}}$ (equivalent for the symmetrical tests). The cyclic tests used to define the contours are denoted with dashed lines. The failure envelope on this contour diagram for symmetrical cyclic loading is defined by $\gamma_{\max }$ $=5 \%$, which is close to the shear strain level where failure was observed in the symmetrical tests consistent with the discussion above. The $\gamma_{\max }$ contours are produced by fitting a simple power law to the data:

$$
\frac{\tau_{\max }}{\mathrm{s}_{\mathrm{u}}}=\mathrm{aN}^{\mathrm{b}}+\mathrm{c}
$$

in which 'a' is a scaling factor that increases with $\tau_{\max } / \mathrm{s}_{\mathrm{u}}$, 'b' controls the curvature of the contours and ' $c$ ' is the limiting (minimum) $\tau_{\max } / \mathrm{s}_{\mathrm{u}}$ at an infinite number of cycles. Curve fitting to the data using equation (2) were obtained through regression analyses using a simple least squares approach. Each of the optimised parameters vary with $\gamma_{\max }$ as summarised in Table 3, together with the coefficient of determination, $\mathrm{R}^{2}$, which is greater than 0.98 for each contour. Various soil element testing studies have identified a threshold shear stress, which is the shear stress level below which failure does not occur even at a high number of cycles (Lefebvre \& LeBoeuf 1988, Sangrey et al. 1969, Larew \& Leonards 1962, Vucetic 1994). This threshold shear stress is linked to the magnitude of the parameter 'c'; examination of Figure 6 and Table 3 indicates that on the basis of these test results, the stress threshold for normally consolidated kaolin is $0.30<\tau_{\max } / \mathrm{s}_{\mathrm{u}}=\tau_{\mathrm{cyc}} / \mathrm{s}_{\mathrm{u}}<0.35$. 
It is noted that each contour is derived from test data with the same $\gamma_{\max }$ and therefore from tests at similar displacement rate. Hence, the effect of shear strain rate discussed above, or different displacement rate in the cyclic tests, on the contour diagrams is expected to be minimal.

\subsection{Non-symmetrical cyclic tests}

\subsubsection{Definition of failure in non-symmetrical cyclic DSS tests}

Six non-symmetrical cyclic DSS tests were conducted at a cyclic stress ratio, CSR $=1$ (i.e. $\tau_{\text {ave }}=\tau_{\text {cyc }}$ ), and two non-symmetrical tests at CSR $=0.26$ and 0.42 (i.e. $\tau_{\text {ave }}>\tau_{\text {cyc }}$ ). Typical results from non-symmetrical tests performed at CSR $=1$ [Cns4] and CSR $=0.26$ [Cns8] are presented in Figure 7 (a) to (e) and Figure 8 (a) to (e) respectively.

Figure 7 (b) and (c) show that in the test with CSR $=1$ ([Cns4]; $\tau_{\mathrm{ave}} / \mathrm{s}_{\mathrm{u}}=\tau_{\mathrm{cyc}} / \mathrm{s}_{\mathrm{u}}=0.41$ ), the change in maximum shear strain per cycle, $\Delta \gamma_{\max } / \Delta \mathrm{N}$, is relatively constant, but increases from $\mathrm{N}=51$. Figure 7 (d) and (e) show that $\sigma_{\mathrm{v}}^{\prime}$ and $\mathrm{G}$ both decrease as the test progresses. As in the symmetrical test on Figure 4, failure can be defined at the point where $\Delta \gamma_{\max } / \Delta \mathrm{N}$ is seen to markedly increase. Failure in test Cns4 is therefore defined at $\mathrm{N}=51$ and is associated with the accumulation of shear strain together with an amount of stiffness degradation. At failure (i.e. at $\mathrm{N}=51) \gamma_{\max } \approx 25 \%$ and $\sigma_{\mathrm{v}}^{\prime}$ and $\mathrm{G}_{\mathrm{cyc}}$ are reduced by $51 \%$ and $48 \%$ respectively. Of the four specimens that failed in the non-symmetrical cyclic DSS tests with CSR = 1 [Cns3 to Cns6], failure, as defined above, was observed at $\gamma_{\max }$ in the range of $23 \%$ to $27 \%$. It is noted that failure at this level of $\gamma_{\max }$ is solely defined at a soil element level without taking into account the design requirements of a structure for displacement.

Figure 8 (b) and (c) show that in the non-symmetrical test with CSR $=0.26$ ([Cns8]; $\tau_{\mathrm{ave}} / \mathrm{S}_{\mathrm{u}}=$ 0.62 and $\left.\tau_{\mathrm{cyc}} / \mathrm{s}_{\mathrm{u}}=0.16\right)$ shear strain develops at the beginning of the test but stabilises after approximately $\mathrm{N}=500$. Figure 8 (d) and (e) indicate that essentially there is no stiffness 
degradation over the $\mathrm{N}=1500$ cycles. Failure therefore did not occur in this test. A stable response was also observed in test Cns7 with a lower average shear stress but with approximately the same cyclic shear stress $\left(\tau_{\mathrm{ave}}=0.36, \tau_{\mathrm{cyc}}=0.15, \mathrm{CSR}=0.42\right)$. The combination of the applied shear stresses in the non-symmetrical tests with $\tau_{\mathrm{ave}}>\tau_{\mathrm{cyc}}$ therefore leads to a stable soil response and can be considered within the threshold where failure does not occur regardless of the number of cycles.

Comparing the response in the symmetrical and non-symmetrical tests with CSR $=1$ at the same $\tau_{\mathrm{cyc}} / \mathrm{s}_{\mathrm{u}}=0.41$ (Figure 4 and Figure 7) reveals that higher shear stiffness degradation and reduction of $\sigma_{\mathrm{v}}^{\prime}$ takes place in the symmetrical test. Minimal cyclic stiffness degradation was observed in the non-symmetrical test with CSR $=0.26$, as shown by Figure 8 . The above observations are consistent with those made by Mao and Fahey (2003), who, on the basis of cyclic simple shear tests on calcareous sediments, observed that non-symmetrical tests lead to less stiffness degradation than symmetrical tests and that the amount of cyclic stiffness degradation decreases with decreasing CSR. Failure in the non-symmetrical test with CSR $=1$ is observed at higher shear strains than in the symmetrical test, in agreement with observations made by Zografou et al. (2016).

\subsubsection{Contour diagrams from non-symmetrical cyclic DSS tests performed at CSR = 1}

Figure 9 shows the contour diagram of $\gamma_{\max }$ based on results from non-symmetrical cyclic DSS tests with CSR $=1$. The contours have been fitted to the measured data from eight nonsymmetrical cyclic DSS tests (including the first stage of two staged tests) with the same level of $\gamma_{\max }$, using equation (2) and the same regressional analysis described above for the symmetrical test interpretation. This resulted in the fitting parameters and coefficients of determination summarised in Table 4. As for the contour diagram from the symmetrical tests, the data points at $\mathrm{N}=1$ have been established from the shear stress-shear strain response in the first quarter of the first cycle in the cyclic tests. The failure envelope is defined at $\gamma_{\max } \approx 25 \%$, 
which is the approximate shear strain level where failure was observed in the non-symmetrical tests as established above.

As discussed above in relation to the symmetrical tests, the threshold shear stress below which failure does not occur irrespective of cycle number is reflected in the parameter 'c' used in equation (2). In the non-symmetrical tests with CSR $=1$, the threshold stress for normally consolidated kaolin was observed at $0.52<\tau_{\max } / \mathrm{s}_{\mathrm{u}}<0.72$, or $0.26<\tau_{\mathrm{cyc}} / \mathrm{s}_{\mathrm{u}}=\tau_{\mathrm{ave}} / \mathrm{s}_{\mathrm{u}}<0.36$.

Selected $\gamma_{\max }$ contours for symmetrical and non-symmetrical cyclic loading are compared on Figure 10 (a) and (b) as a function of normalised $\tau_{\max }$ and $\tau_{\text {cyc }}$ respectively. From the figure it is evident that for a given level of $\tau_{\max }$ or $\tau_{\text {cyc }}$ and number of cycles, shear strains are higher for non-symmetrical cyclic loading than for symmetrical cyclic loading. For example, at $\tau_{c y c} / \mathrm{s}_{\mathrm{u}}=$ 0.50 the failure envelope of $\gamma_{\max }=5 \%$ (symmetrical loading) is reached at $\mathrm{N}=25$ while the failure envelope of $\gamma_{\max }=25 \%$ (non-symmetrical loading) is reached at $\mathrm{N}=10$. Given that the cyclic shear strength is defined at the point where the accumulation procedure intersects the failure envelope on a contour diagram, Figure 10 shows that (for CSR $=1$ ) non-symmetrical cyclic loading is a more onerous load case than symmetrical cyclic loading, despite the higher $\gamma_{\max }$ failure criterion. However, as failure in the non-symmetrical tests is associated with $\gamma_{\max }$ $=25 \%$, the calculated cyclic shear strength or $N_{\text {eq }}$ will be higher than adopting the $\gamma_{\max }=5 \%$ failure criterion used in the symmetrical tests, which may permit for a more economical foundation design.

Also shown on Figure 10 (a) and (b) are data from the non-symmetrical tests performed at CSR $=0.26\left([\right.$ Cns 8$] ; \tau_{\mathrm{ave}} / \mathrm{s}_{\mathrm{u}}=0.62$ and $\left.\tau_{\mathrm{cyc}} / \mathrm{s}_{\mathrm{u}}=0.16\right)$ and CSR $=0.42\left(\left[\right.\right.$ Cns7]; $\tau_{\mathrm{ave}} / \mathrm{s}_{\mathrm{u}}=0.36$ and $\tau_{\mathrm{cyc}} / \mathrm{s}_{\mathrm{u}}=0.15$ ). Figure 10 (a) shows that the selected value of $\gamma_{\max }=3 \%$ in the test with CSR $=$ 0.42 plots close to the $\gamma_{\max }=3 \%$ contour for CSR $=1$. However, the selected value of $\gamma_{\max }=$ $5 \%$ in the test with CSR $=0.26$, that reached a stable response, plots on approximately the $\gamma_{\max }$ 
$=25 \%$ contour for CSR $=1$ (i.e. the failure envelope). The selected data on Figure 10 (b) plot below all contours. Hence the response in non-symmetrical tests appears to depend on the CSR, and therefore the behaviour at a CSR less than unity may not be predicted accurately by contour diagrams derived from non-symmetrical tests with CSR $=1$.

\subsection{Staged symmetrical cyclic DSS tests}

\subsubsection{Results}

As detailed in Table 2, the test programme included four staged symmetrical cyclic DSS tests. Test StCs1 reached failure in the last parcel while tests StCs2, StCs3 and StCs4 were performed at slightly lower amplitudes so that failure is not reached. The latter tests form the basis for assessing the effect of stress history and had parcels of the same amplitude $\left(\tau_{\mathrm{cyc}} / \mathrm{s}_{\mathrm{u}}=\tau_{\mathrm{max}} / \mathrm{s}_{\mathrm{u}}=\right.$ 0.25, 0.35 and 0.45), with the parcels arranged in ascending order in test StCs2, descending order in test StCs3, and ascending followed by descending order in test StCs4. Each of the three tests involved 175 cycles, 100 at $\tau_{\max } / \mathrm{s}_{\mathrm{u}}=0.25,50$ at $\tau_{\max } / \mathrm{s}_{\mathrm{u}} \approx 0.35$ and 25 at $\tau_{\max } / \mathrm{s}_{\mathrm{u}}=0.45$. The fourth staged symmetrical test [StCs1] also employed parcels of ascending order but with $\tau_{\max } / \mathrm{s}_{\mathrm{u}}=0.22$ for $\mathrm{N}=100, \tau_{\max } / \mathrm{s}_{\mathrm{u}}=0.39$ for $\mathrm{N}=50$ and $\tau_{\max } / \mathrm{s}_{\mathrm{u}}=0.55$ for $\mathrm{N}=25$.

Figure 11, Figure 12 and Figure 13 present the applied shear stresses and induced shear strains in the three staged tests with parcels of the same shear stress amplitude [StCs2, StCs3, StCs4]. The response of the maximum shear strain in the three tests is compared in Figure 14. It is noted that the variation of shear strain rate between the parcels of the staged tests is significantly less than a log cycle and, based on the discussion above, it is not expected to have an effect on the results. From the figures it can be observed that failure, as defined based on the uniform symmetrical tests, was not reached in these tests. The maximum shear strain is $\gamma_{\max }=3.4 \%$, which was measured in test StCs2 where the parcels were arranged in ascending order. The 
maximum shear strain in the other two tests are similar; $\gamma_{\max }=2.4 \%$ and $2.3 \%$ in tests StCs3 and StCs4 respectively.

Figure 15 (a), (b) and (c) show the shear stress-shear strain loops at the beginning and at the end of each parcel in the staged symmetrical tests. Cyclic stiffness reduced by $65 \%$ of the initial value in test StCs2 (parcels arranged in ascending order), by $55 \%$ of the initial value in test StCs4 (parcels arranged in ascending order and then descending order) and by $44 \%$ of the initial value in test StCs3 (parcels arranged in descending order). These observations indicate that arranging parcels in ascending order leads to the highest shear strain and cyclic stiffness degradation, consistent with observations made by Andersen (2015). However, as a real storm intensifies and then abates, a more realistic idealisation may be ascending and then descending parcels of shear stress intensity (i.e. as in test in StCs4). On the basis of the results presented in Figure 11 to Figure 15, such an approach may be less conservative than the accumulation procedure approach of arranging parcels in ascending order.

\subsubsection{Comparison of $\gamma_{\max }$ in staged symmetrical DSS tests with accumulation procedure predictions}

Table 5 compares the maximum values of $\gamma_{\max }$ measured in the staged symmetrical cyclic DSS tests with $\gamma_{\max }$ predicted by the accumulation procedure. Implementation of the accumulation procedure for the staged tests with $\tau_{\max } / \mathrm{s}_{\mathrm{u}}=0.22,0.39$ and 0.55 [StCs1] and $\tau_{\max } / \mathrm{s}_{\mathrm{u}} \approx 0.25,0.35$ and 0.45 [StCs2, StCs3 and StCs4] is illustrated on Figure 16. As required by the accumulation procedure, the staged tests are re-arranged in parcels in ascending order. As the first parcel with the lowest amplitude $\left(\tau_{\max } / \mathrm{s}_{\mathrm{u}}=0.22\right.$ or 0.25 ) induced only elastic shear strains, this parcel was not considered in the accumulation procedure. This is consistent with the NGI computer-based method for arranging the cycles of an irregular cyclic load history into parcels, in which the 
cycles with amplitudes lower than $30 \%$ of the maximum cyclic load are ignored (NorenCosgriff et al. 2015).

Figure 16 shows that the accumulation procedure predicts failure for test StCs1 as the graphical construction intersects the failure envelope, such that the calculated $\gamma_{\max }=5 \%$. The cyclic shear strength is therefore the final shear stress level, i.e. $\tau_{\mathrm{max}, \mathrm{f}} / \mathrm{s}_{\mathrm{u}}=0.55$, and the equivalent number of cycles is $\mathrm{N}_{\mathrm{eq}}=12$. The measured maximum shear strain at the end of the final parcel was $\gamma_{\max }=5 \%$ at $\mathrm{N}=15$ cycles, which is in agreement with the calculated $\gamma_{\max }=5 \%$ at $\mathrm{N}_{\mathrm{eq}}=12$. The maximum shear strain estimated using the accumulation procedure for tests StCs2, StCs3 and StCs4 is $\gamma_{\max }=2.4 \%$. This is the same as the measured maximum shear strain in test StCs3 (where the parcels were arranged in descending order), very close to the maximum shear strain, $\gamma_{\max }=2.3 \%$ in test StCs4 (in which the parcels ascended and then descended), but almost 30\% lower than $\gamma_{\max }=3.4 \%$ measured in test StCs2, where the parcels were arranged in ascending order as in the accumulation procedure and with $\tau_{\max / \mathrm{S}_{\mathrm{u}}}=0.36$ instead of 0.35 .

Good agreement appears between the observed response of the normally consolidated kaolin tested in this study of the four symmetrical staged cyclic DSS tests and the response predicted by the accumulation procedure. Dyvik et al. (1981) reached similar conclusions based on results from staged symmetrical cyclic DSS tests on normally consolidated Pacific Illite clay. Boukpeti et al. (2014) also found that the accumulation procedure is accurate in calculating the magnitude of the maximum shear strains for a carbonate silt under staged symmetrical cyclic loading for $\tau_{\mathrm{cyc}} / \sigma_{\mathrm{v} 0}^{\prime} \leq 0.3\left(\tau_{\mathrm{cyc}} / \mathrm{s}_{\mathrm{u}} \leq 0.6\right)$, but under predicts the maximum shear strains at higher shear stresses. 


\subsection{Staged non-symmetrical cyclic DSS tests with CSR $=1$}

\subsubsection{Results}

Two staged non-symmetrical tests with CSR $=1$ were performed under parcels of $\tau_{\max } / \mathrm{s}_{\mathrm{u}}=$ 0.75 and 0.86 [StCns1], and 0.80 and 0.70 [StCns2]. The applied shear stresses and measured shear strains from these tests are shown in Figure 17 (a), (b) and (c). Similarly with the staged symmetrical tests, the variation of shear strain rate between the parcels of the staged tests is significantly less than a log cycle and is not expected to have an effect on the results. The figure shows that failure, as defined based on the uniform non-symmetrical tests, was not reached in these tests. The staged test with parcels in ascending order [StCns1] resulted in a maximum shear strain $\gamma_{\max }=14.0 \%$, higher than $\gamma_{\max }=9.9 \%$ measured at the end of test StCns2, in which the parcels were arranged in descending order and the shear stress levels were slightly lower. Figure 18 (a) and (b) show the shear stress-shear strain loops at the beginning and end of each parcel, from which it can be observed that higher stiffness degradation occurred in the staged non-symmetrical test with parcels in ascending order. The values of $G_{c y c}$, reduced by approximately $54 \%$ of the initial value in test StCns1 (parcels in ascending order), but only by approximately 38\% in test StCns2 (parcels in descending order). These results are consistent with the staged symmetrical cyclic DSS tests - parcels arranged in ascending order lead to higher $\gamma_{\max }$ and cyclic stiffness degradation - albeit that the non-symmetrical test results also include a contribution due to the slightly different shear stress levels.

\subsubsection{Comparison of $\gamma_{\max }$ in staged symmetrical DSS tests with accumulation procedure predictions}

Figure 19 shows the strain contour diagram derived from the non-symmetrical cyclic DSS tests together with the retrospective predicted maximum shear strain for tests StCns1 and StCns2. The maximum measured and predicted values of $\gamma_{\max }$ are summarised in Table 6. It can be seen that the accumulation procedure overpredicts the maximum shear strain for the staged non- 
symmetrical CDSS tests by approximately $20 \%$ for test StCns2 (in which the parcels where arranged in descending order), and by approximately 50\% for test StCns1 (in which the parcels where arranged in ascending order and the maximum shear stress level was higher). These significant over predictions contrast markedly with the case of the staged symmetrical cyclic tests, in which the accumulation procedure either accurately predicted, or (for the test where the parcels where arranged in ascending order) under predicted the maximum shear strain. This observation warrants further attention, noting that these preliminary conclusions are drawn on the basis of the two cyclic sequences considered.

\section{Conclusions}

A suite of stress-controlled cyclic DSS tests have been performed on normally consolidated kaolin cay under symmetrical and non-symmetrical cyclic loading. Contour diagrams of maximum shear strain versus number of cycles have been derived for these two cases that can be used for the interpretation of model test data on kaolin. Staged cyclic DSS tests with parcels of uniform amplitude in ascending, descending and ascending followed by descending magnitude have also been performed to compare the observed soil response with the response predicted by the accumulation procedure.

For the testing conditions considered in this paper, the following conclusions can be made:

- $\quad$ Reduced stiffness degradation occurs under non-symmetrical cyclic shearing with CSR = 1 compared to under symmetrical cyclic shearing, while failure occurs at higher values of $\gamma_{\max }$ but at a lower number of cycles - for a similar cyclic shear stress level. This conclusion highlights the importance of adopting values of CSR that are relevant to the shear stresses applied on the soil elements below offshore foundations during cyclic loading. 
- The failure envelope on a contour diagram can be defined at a higher shear strain level for non-symmetrical cyclic loading than under symmetrical loading. This conclusion is relevant for the geotechnical design of shallow foundations for offshore structures with relatively high tolerance to horizontal displacement, such as offshore subsea structures that are not connected to a superstructure (such as umbilical termination assemblies or zero radius bend triggers), offering potential efficiencies in foundation design.

- The soil response in the non-symmetrical tests with high $\tau_{\text {ave }}$ and low $\tau_{\text {cyc }}$, CSR $=0.26$ and 0.42 , cannot be predicted by the strain contour diagram based on non-symmetrical tests with CSR $=1$. The shear strain response in these tests was stable indicating that the applied combination of $\tau_{\mathrm{ave}}$ and $\tau_{\mathrm{cyc}}$, is within the threshold of shear stresses that do not cause failure. The use of the traditional accumulation procedure for the geotechnical design of subsea foundations subjected to cyclic loading with high average shear stress and low cyclic shear stress (such as zero radius bend triggers) may lead to unnecessarily conservative foundation design.

- The accumulation procedure predicted reasonably well the final, or maximum, shear strain at the end of the staged symmetrical cyclic DSS tests but over predicted the shear strain at the end of the staged non-symmetrical cyclic DSS tests with CSR $=1$ for the non-symmetrical cyclic sequences considered. Greater over prediction by the accumulation procedure, by approximately 50\%, was noted in the sequence with parcels in ascending order. This indicates that the traditional accumulation approach provides a conservative, if not the most efficient, design solution.

\section{Acknowledgements}

This work forms part of the activities of the Centre for Offshore Foundation Systems (COFS). Established in 1997 under the Australian Research Council's Special Research Centres 
Program. Supported as a node of the Australian Research Council's Centre of Excellence for Geotechnical Science and Engineering, and through the Fugro Chair in Geotechnics, the Lloyd's Register Foundation Chair and Centre of Excellence in Offshore Foundations and the Shell EMI Chair in Offshore Engineering. The work presented in this paper is supported through ARC grant CE110001009. This support is gratefully acknowledged. The authors are also grateful to Associate Professor Antonio Carraro, former Academic Supervisor of the UWA Geotechnical Testing Laboratory, for his guidance during the laboratory testing. 
Figure captions

Figure 1 (a) Shear stress and (b) shear strain components in stress-controlled cyclic DSS tests

Figure 2 (a) Irregular cyclic load history transformed into parcels of cyclic shear stress, (b) the accumulation procedure for the cyclic stress history on a contour diagram of $\gamma_{\max }$ and (c) assessment of $\Delta \gamma$ due to stress increment between parcels from stress-strain response at $\mathrm{N}=1$

Figure 3 Geocomp DSS apparatus: (a) schematic representation, and (b) polycarbonate top cap and rod and Teflon coated stacked ringsFigure 4 Typical results from a symmetrical cyclic DSS tests under $\tau_{\max } / \mathrm{s}_{u}=0.41$ [Cs3]: a) input shear stress and measured response during cycling and (b) stress-strain response at cycle numbers, $\mathrm{N}=1,10,100$ and 229

Figure 5 Stress-strain response at $\mathrm{N}=1$ of symmetrical cyclic DSS tests and in monotonic DSS tests performed at $0.1 \mathrm{~mm} / \mathrm{min}, 1 \mathrm{~mm} / \mathrm{min}$ and $2.5 \mathrm{~mm} / \mathrm{min}$ for a) $\gamma: 0-5 \%$ and b) $\gamma: 0-20 \%$

Figure 6 Contour diagram of $\gamma_{\max }$ derived from symmetrical cyclic DSS tests with CSR $=\infty$

Figure 7 Typical results from non-symmetrical cyclic DSS tests under $\tau_{\mathrm{ave}} / \mathrm{s}_{\mathrm{u}}=0.41$ and CSR

$=1$ [Cns4]: a) input shear stress and measured response during cycling and (b) stress-strain response at cycle numbers, $\mathrm{N}=2,10$ and 51

Figure 8 Typical results from non-symmetrical cyclic DSS tests under $\tau_{\mathrm{ave}} / \mathrm{s}_{\mathrm{u}}=0.62$ and CSR $=0.26$ [Cns8]: a) input shear stress and measured response during cycling and (b) stress-strain response at cycle numbers, $\mathrm{N}=2,10,100$ and 1500

Figure 9 Contour diagram of $\gamma_{\max }$ derived from non-symmetrical cyclic DSS tests with CSR=1

Figure 10 Comparison of contour diagrams from symmetrical tests and non-symmetrical tests (with CSR=1) as a function of a) $\tau_{\max } / \mathrm{s}_{\mathrm{u}}$ and b) $\tau_{\text {cyc }} / \mathrm{s}_{\mathrm{u}}$ 
Figure 11 Results from staged symmetrical cyclic DSS tests under $\tau_{\max } / \mathrm{s}_{u}=0.25,0.36$ and 0.45 [StCs2]

Figure 12 Results from staged symmetrical cyclic DSS tests under $\tau_{\max } / \mathrm{s}_{\mathrm{u}}=0.45,0.35$ and 0.25 [StCs3]

Figure 13 Results from staged symmetrical cyclic DSS tests under $\tau_{\max } / s_{u}=0.25,0.35,0.45$, 0.35 and 0.25 [StCs4]

Figure 14 Comparison of $\gamma_{\max }$ from staged symmetrical cyclic DSS tests

Figure 15 Stress-strain loops at the beginning and at the end of each parcel of staged symmetrical cyclic DSS tests under: (a) $\tau_{\max } / \mathrm{s}_{\mathrm{u}}=0.25,0.36$ and 0.45 [StCs2] (b) $\tau_{\max } / \mathrm{s}_{\mathrm{u}}=0.45$, 0.35 and 0.25 [StCs3] and (c) $\tau_{\max } / s_{u}=0.25,0.35,0.45,0.35$ and 0.25 [StCs4]

Figure 16 Accumulation procedure for the staged symmetrical cyclic DSS tests

Figure 17 Results from staged non-symmetrical cyclic DSS tests under $\tau_{\max } / \mathrm{s}_{\mathrm{u}}=0.75 / 0.86$ and $\tau_{\max } / \mathrm{s}_{\mathrm{u}}=0.80 / 0.70$ : a) $\tau / \mathrm{su}_{\mathrm{u}}$, and (b) $\gamma$

Figure 18 Stress-strain loops at the beginning and at the end of each parcel of the staged nonsymmetrical cyclic DSS tests under: (a) $\tau_{\max } / \mathrm{s}_{\mathrm{u}}=0.75 / 0.86$ [StCns1] and (b) $\tau_{\max } / \mathrm{s}_{\mathrm{u}}=0.80 / 0.70$ [StCns2]

Figure 19 Accumulation procedure for the staged non-symmetrical cyclic DSS tests 
Table captions

Table 1 Properties of kaolin clay (Stewart 1992)

Table 2 Overview of direct simple shear tests carried out for this study

Table 3 Fitting parameters for contour diagram of $\gamma_{\max }$ based on symmetrical cyclic DSS tests for $\mathrm{CSR}=\infty($ from Eqn.2)

Table 4 Fitting parameters for contour diagram of $\gamma_{\max }$ based on non-symmetrical cyclic DSS tests for CSR=1 (from Eqn. 2)

Table 5 Summary of the maximum values of $\gamma_{\max }$ measured in the staged symmetrical cyclic DSS tests and the values predicted by the accumulation procedure

Table 6 Summary of the maximum values of $\gamma_{\max }$ measured in the staged non-symmetrical cyclic DSS tests and the values predicted by the accumulation procedure 


\section{$7 \quad$ References}

Acosta-Martinez, H.E., \& Gourvenec, S.M. (2008). Response of skirted foundations for buoyant facilities subjected to cyclic uplift loading. 18th International Offshore and Polar Engineering Conference,Vancouver, Canada, 2, 705-712

Andersen, K.H. (1976). Behaviour of clay subjected to undrained cyclic loading. International Conference on the Behaviour of Offshore Structures, BOSS'76, Trondheim, Norway, Norwegian Institute of Technology, Trondheim, Norway, 1, 392-403.

Andersen, K.H., Kleven, A. \& Heien, D., (1988). Cyclic soil data for design of gravity structures. Journal of Geotechnical Engineering, 114 (5), 517-539.

Andersen, K.H., Dyvik, R., Lauritzsen, R., Heien, D., Harvik, L. \& Amundsen, T. (1989). Model tests of gravity platforms. II: Interpretation. Journal of Geotechnical Engineering, 115 (11), 1550-1568.

Andersen, K.H., Dyvik, R., Schrøder, K., Hansteen, O.E., \& Bysveen, S. (1993). Field tests of anchors in clay. II: Predictions and interpretation. Journal of Geotechnical Engineering, 119 (10), 1532-1549

Andersen, K.H., Jeanjean, P., Luger, D. \& Jostad, H.P., (2005). Centrifuge tests on installation of suction anchors in soft clay. Ocean Engineering, 32 (7), 845-863.

Andersen, K.H. (2009). Bearing capacity under cyclic loading - offshore, along the coast, and on land. The 21st Bjerrum Lecture presented in Oslo, 23 November 2007. Canadian Geotechnical Journal, 46 (5), 513-535.

Andersen, K.H., Puech, A.A. \& Jardine, R. J. (2013). Cyclic resistant geotechnical design and parameter selection for offshore engineering and other applications. ISSMGE conference - TC 209 Workshop - Design for cyclic loading: piles and other foundations - Paris, 9-44

Andersen K.H. (2015). Cyclic soil parameters for offshore foundation design, In Proceedings of the Frontiers in Offshore Geotechnics III, Oslo, 5-82

Ansal, A. \& Erken, A. (1989). Undrained Behavior of clay under cyclic shear stresses. Journal of Geotechnical Engineering, 115 (7), 968-983.

ASTM D6528-07 Standard Test Method for Consolidated Undrained Direct Simple Shear Testing of Cohesive Soils (Withdrawn 2016).

Bjerrum, L. \& Landva, A. (1966). Direct simple shear-tests on a Norwegian quick clay, Géotechnique, 16 (1), 1 20.

Boukpeti, N, Lehane, B. \& Carraro, J.A.H (2014). Strain accumulation procedure during staged cyclic loading of carbonate sediments, ASME 2014 33rd International Conference on Ocean, Offshore and Arctic Engineering, OMAE 2014, New York, 3, 1-7.

Carraro, J.A.H. (2017). Analysis of simple shear tests with cell pressure confinement. Geomechanics and Geoengineering, 12 (3), 169-180.

Casagrande, A. \& Wilson S.D. (1951). Effect of rate of loading on the strength of clays and shales at constant water content. Géotechnique, 2, 251-263

Chen, W. \& Randolph M.F. (2007). Uplift capacity of suction caissons under sustained and cyclic loading in soft clay. Journal Geotechnical Geoenvironmental Engineering, ASCE, 133 (11), 1352-1363.

Clukey E.C., Morrison M. J., Garnier J. \& Corte J.F (1995). The response of suction caissons in normally consolidated clays to cyclic TLP loading conditions. Offshore technology conference, Houston, OTC 7796, 909-918.

Dyvik R., Zimmie T. F. \& Schimelfenyg P. (1981). Cyclic Simple Shear Behavior of Fine Grained Soils. In Proceedings of International Conference on Recent Advances in Geotechnical Earthquake Engineering and Soil Dynamics, St. Louis, 101-106. 
Dyvik R., Berre T., Lacasse S. \& Raadim B. (1987). Comparison of truly undrained and constant volume direct simple shear tests. Géotechnique 37 (1), 3-10.

Geocomp Corporation (2012). Control and Report Software for Fully Automated Cyclic Direct Simple Shear Tests on ShearTrac-II DSS Systems using Windows ${ }^{\circledR X P / V i s t a / 7, ~ C y c l i c ~ D i r e c t ~ S i m p l e ~ S h e a r-~ U s e r ' s ~ M a n u a l . ~}$

Graham J., Crooks J.H.A. \& Bell A.L. (1983). Time effects on the stress-strain behavior of natural soft clays. Géotechnique, 33 (3), 327-340.

Ho J. (2013). Cyclic and post-cyclic behaviour of soft clays. PhD thesis, National University of Singapore.

Hsu, C. \& Vucetic, M. (2006). Threshold shear strain for cyclic pore-water pressure in cohesive soils. Journal of Geotechnical and Geoenvironmental Engineering, 132 (10), 1325-1335.

Idriss I.M., Dobry R. \& Singh R.D. (1978). Nonlinear behavior of soft clays during cyclic loading. Journal of the Geotechnical Engineering Division, 104 (12), 1427-1447.

Jardine R.J., Puech A. \& Andersen K.H., (2012). Cyclic loading of offshore piles: potential effects and practical design. In 7th Int. Conf. on Offshore Site Investigations and Geotechnics: Integrated Geotechnologies-Present and Future.

Joer H.A., Erbrich C.T., \& Sharma S.S. (2011). A new interpretation of the simple shear test. In Proceedings of Frontiers in Offshore Geotechnics II, Perth, 353-358.

Larew, H.G. \& Leonards G.G. (1962). A strength criterion for repeated loads. In Proceedings of the 41st Annual Meeting of the Highway Research Board, Washington, D.C, 41, 526-556.

Lefebvre G. \& LeBoeuf D. (1987). Rate effects of cyclic loading of sensitive clays. Journal of Geotechnical Engineering, 113 (5), 476-489.

Lefebvre G. \& LeBoeuf D. (1988) Stability threshold for cyclic loading of saturated clay. Canadian Geotechnical Journal, 26, 122-131.

Lunne T. \& Andersen K.H. (2007). Soft clay shear strength parameters for deepwater geotechnical design. In Proceedings of the 6th International Offshore Site Investigation and Geotechnics Conference: Confronting New Challenges and Sharing Knowledge, 11-13 September 2007, London, UK.

Mao, X., \& Fahey M. (2003). Behaviour of calcareous soils in undrained cyclic simple shear. Géotechnique, 53 (8), 715-727

Mayne, P.W. (1985). A review of undrained strength in direct simple shear. Soils and foundations, 25 (3), 64-72.

Meimon Y. \& Hicher P.Y. (1980). Mechanical behaviour of clays under cyclic loading. In International Symposium on Soils under Cyclic and Transient Loading, 77-87.

Mohr, H., Draper, S. \& White, D. (2013) Free field sediment mobility on Australia’s North West Shelf. In 32nd International Conference on Ocean, Offshore and Arctic Engineering, Nantes, France, OMAE2013-11490.

Noren-Cosgriff K., Jostad H.P. \& Madshus C. (2015). Idealized load composition for determination of cyclic undrained degradation of soils, In Proceedings of the Frontiers in Offshore Geotechnics III, Oslo, 10971102.

Ohara S. \& Matsuda H. (1988). Study on the settlement of saturated clay layer induced by cyclic shear. Soils and Foundations, 28 (3), 103-113.

Peek, R. \& Kristiansen N. (2009) Zero-radius bend method to trigger lateral buckles. Journal of Transportation Engineering, 135 (12), 946-952. 
Randolph, M.F., O'neill, M.P., Stewart, D.P. \& Erbrich, C. (1998). Performance of suction anchors in fine-grained calcareous soils. In Offshore technology conference.

Randolph, M.F. (2012). Offshore design approaches and model tests for sub-failure cyclic loading of foundations. Mechanical Behaviour of Soils Under Environmentally Induced Cyclic Loads, 441-480.

Sangrey D. A., Henkel D. J. \& Esrig M. I. (1969). The effective stress response of a saturated clay soil to repeated loading. Canadian Geotechnical Journal, 1969, 6 (3), 241-252.

Sheahan T.C., Ladd C.C., \& Germaine J.T. (1996). Rate-dependent undrained shear behavior of saturated clay. Journal of Geotechnical Engineering, 122 (2), 99-108.

Stewart, D. P. (1992). Lateral loading of piled bridge abutments due to embankment construction. PhD thesis, The University of Western Australia.

Vaid, Y.P. \& Campanella R.G. (1977). Time-dependent behavior of undisturbed clay. Journal of Geotechnical and Geoenvironmental Engineering, 103 (GT7), 693-709.

Vucetic, M. (1994). Cyclic Threshold Shear Strains in Soils. Journal of Geotechnical Engineering, ASCE 120 (12), 2208-2228.

Watson P. G. (1999) Performance of skirted foundations for offshore structures. PhD thesis, University of Western Australia, Australia.

Watson, P.G. \& Randolph, M.F. (2006). A centrifuge study into cyclic loading of caisson foundations. In Proceedings of the International Conference Physical Modelling in Geotechnics, Hong Kong, 4-6.

Zografou D., Boukpeti N., Gouvernec S. \& O’Loughlin C. (2016). Definition of failure in cyclic direct simple shear tests on normally consolidated kaolin clay and presentation of shear strain contour diagrams. In proceedings of the 5th International Conference on Geotechnical and Geophysical Site Characterisation (ISSMGE TC-102 ISC’5), Gold Coast, Queensland, Australia, 5-9 September 2016, 1, 583-588.

Zografou D., Gourvenec S.M., O’Loughlin C.D. \& Banimahd M. (2018). Applicability of the shear strain accumulation procedure for the foundation design of zero-radius bend triggers against cyclic loading (submitted to Ocean Engineering - under review ) 
Table 1 Properties of kaolin clay (Stewart 1992)

\begin{tabular}{|l|l|}
\hline Liquid limit, LL (\%) & 61 \\
\hline Plastic limit, PL (\%) & 27 \\
\hline Specific gravity, $\mathrm{G}_{\mathrm{s}}$ & 2.6 \\
\hline Critical state friction constant, $\mathrm{M}$ & 0.92 \\
\hline Slope of normal consolidation line, $\lambda$ & 0.205 \\
\hline Slope of swelling line, $\kappa$ & 0.044 \\
\hline
\end{tabular}


Table 2 Overview of direct simple shear tests carried out for this study

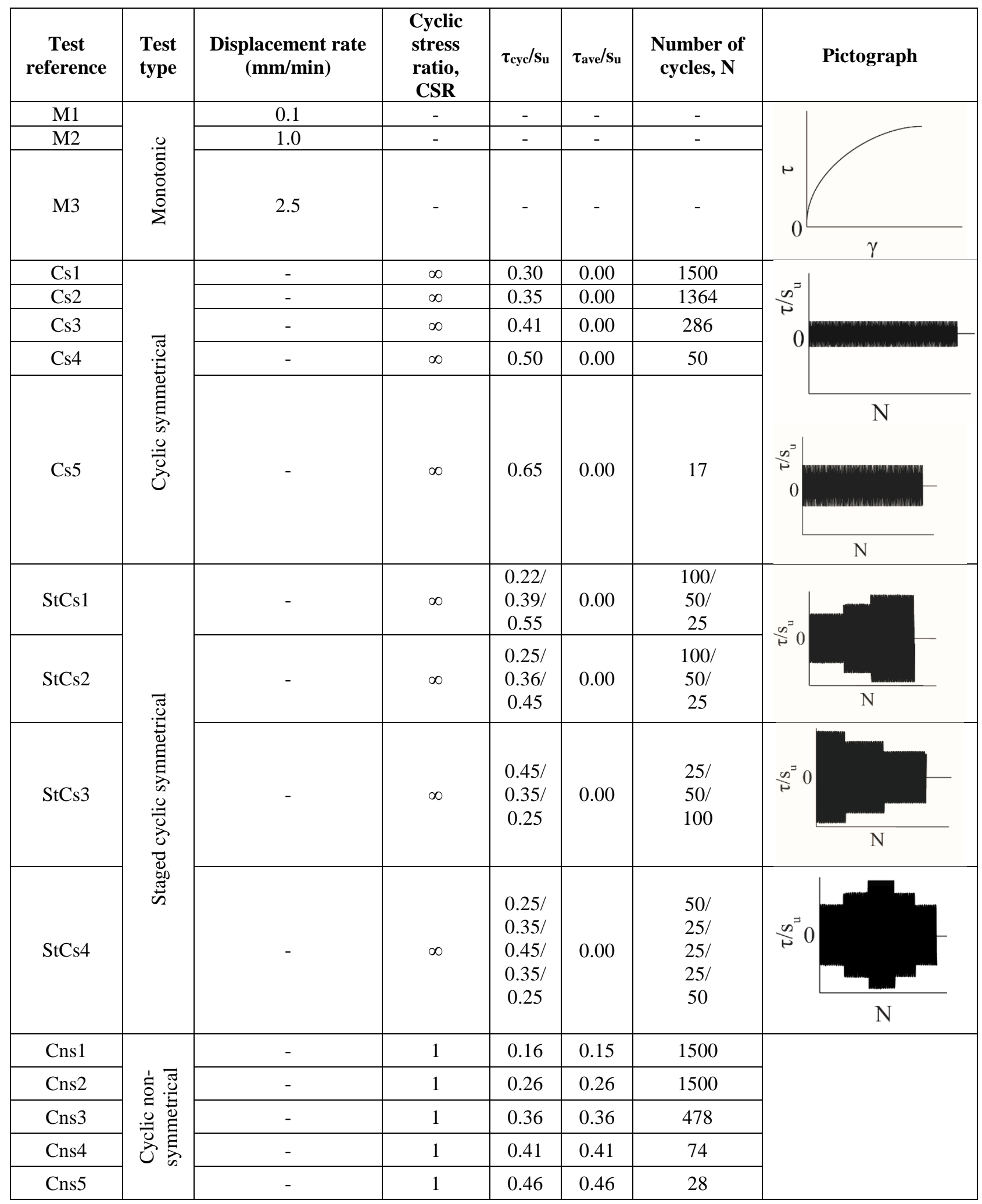




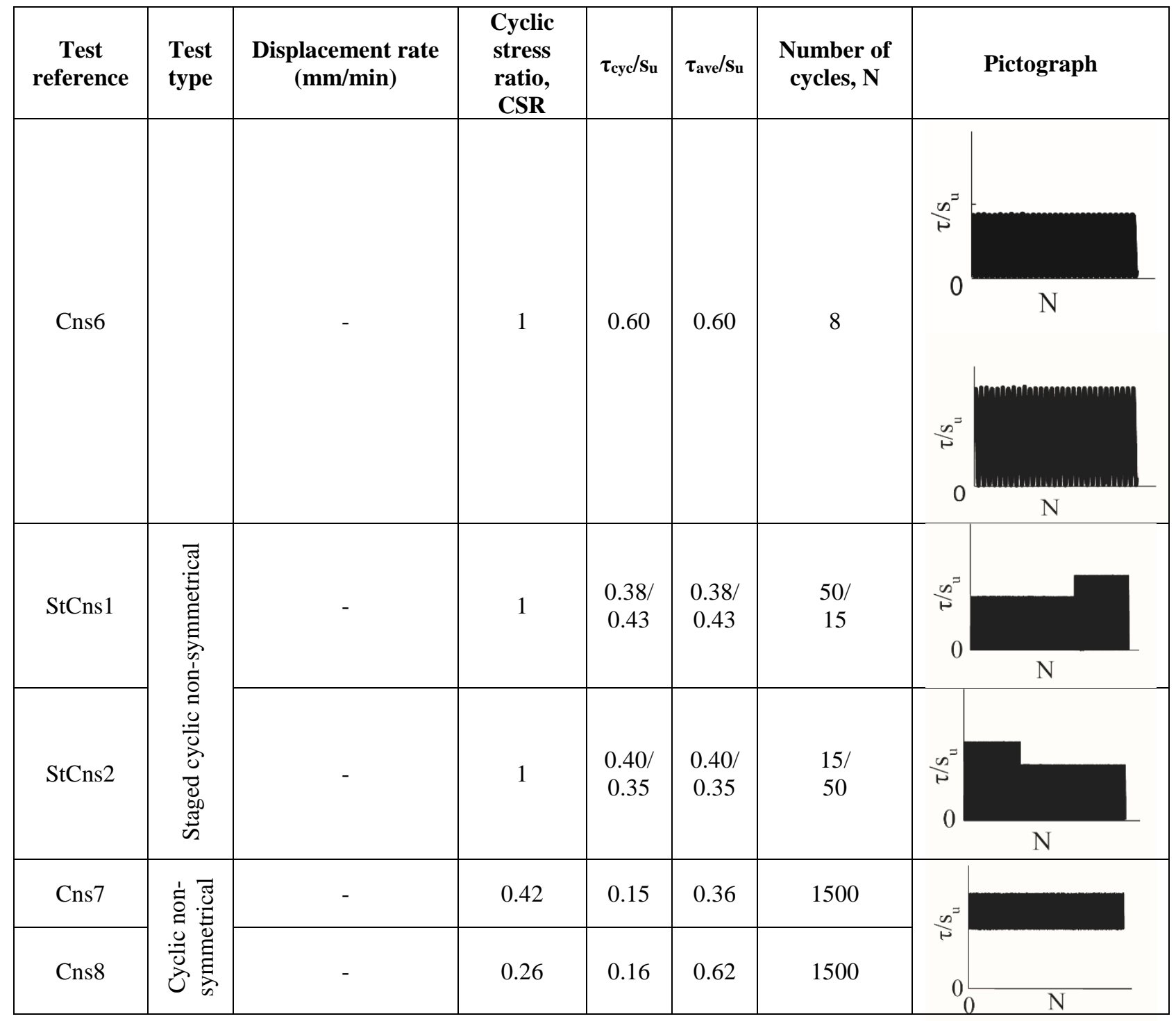


Table 3 Fitting parameters for contour diagram of $\gamma_{\max }$ based on symmetrical cyclic DSS tests for CSR $=\infty$ (from Eqn.2)

\begin{tabular}{|c|c|c|c|c|}
\hline$\gamma_{\max }(\mathbf{\% )}$ & $\mathbf{a}$ & $\mathbf{b}$ & $\mathbf{c}$ & $\mathbf{R}^{\mathbf{2}}$ \\
\hline 0.5 & 0.00 & 0.00 & 0.250 & - \\
\hline 1 & 0.17 & -0.24 & 0.287 & 0.983 \\
\hline 2 & 0.29 & -0.25 & 0.310 & 0.982 \\
\hline 3 & 0.40 & -0.28 & 0.315 & 0.993 \\
\hline 5 & 0.54 & -0.35 & 0.325 & 0.991 \\
\hline
\end{tabular}


Table 4 Fitting parameters for contour diagram of $\gamma_{\max }$ based on non-symmetrical cyclic DSS tests for CSR=1 (from Eqn. 2)

\begin{tabular}{|c|c|c|c|c|}
\hline$\gamma_{\max } \mathbf{( \% )}$ & $\mathbf{a}$ & $\mathbf{b}$ & $\mathbf{C}$ & $\mathbf{R}^{\mathbf{2}}$ \\
\hline 1 & 0.00 & 0.00 & 0.310 & - \\
\hline 2 & 0.21 & -0.18 & 0.400 & 0.871 \\
\hline 3 & 0.30 & -0.23 & 0.445 & 0.927 \\
\hline 4 & 0.31 & -0.28 & 0.520 & 0.953 \\
\hline 5 & 0.35 & -0.32 & 0.570 & 0.867 \\
\hline 7 & 0.44 & -0.33 & 0.590 & 0.999 \\
\hline 10 & 0.53 & -0.34 & 0.600 & 0.999 \\
\hline 15 & 0.66 & -0.35 & 0.605 & 0.999 \\
\hline 20 & 0.77 & -0.36 & 0.608 & 0.999 \\
\hline
\end{tabular}


Table 5 Summary of the maximum values of $\gamma_{\max }$ measured in the staged symmetrical cyclic DSS tests and the values predicted by the accumulation procedure

\begin{tabular}{|c|c|c|c|c|c|c|}
\hline $\begin{array}{c}\text { Test } \\
\text { reference }\end{array}$ & Parcel & $\tau_{\max } / \mathbf{s}_{\mathbf{u}}$ & $\mathbf{N}$ & $\begin{array}{c}\text { Maximum } \\
\text { measured } \\
\gamma_{\max }(\%)\end{array}$ & $\begin{array}{c}\text { Maximum } \\
\text { predicted } \gamma_{\max } \\
(\%)\end{array}$ & Predicted $\mathrm{N}_{\mathrm{eq}}$ \\
\hline \multirow{3}{*}{ StCs1 } & 1 & 0.22 & 100 & & \multirow[t]{3}{*}{ (2) } & \multirow{3}{*}{12} \\
\hline & 2 & 0.39 & 50 & & & \\
\hline & 3 & 0.55 & 15 & 5 (failure) & & \\
\hline \multirow{3}{*}{ StCs2 } & 1 & 0.25 & 100 & & \multirow{3}{*}{2.4} & \multirow{3}{*}{28} \\
\hline & 2 & 0.36 & 50 & & & \\
\hline & 3 & 0.45 & 25 & 3.4 & & \\
\hline \multirow{3}{*}{ StCs3 } & 1 & 0.45 & 25 & 2.4 & \multirow{3}{*}{2.4} & \multirow{3}{*}{28} \\
\hline & 2 & 0.35 & 50 & & & \\
\hline & 3 & 0.25 & 100 & & & \\
\hline \multirow{5}{*}{ StCs4 } & 1 & 0.25 & 50 & & \multirow{5}{*}{2.4} & \multirow{5}{*}{28} \\
\hline & 2 & 0.35 & 25 & & & \\
\hline & 3 & 0.45 & 25 & 2.3 & & \\
\hline & 4 & 0.35 & 25 & & & \\
\hline & 5 & 0.25 & 50 & & & \\
\hline
\end{tabular}


Table 6 Summary of the maximum values of $\gamma_{\max }$ measured in the staged non-symmetrical cyclic DSS tests and the values predicted by the accumulation procedure

\begin{tabular}{|c|c|c|c|c|c|c|}
\hline $\begin{array}{c}\text { Test } \\
\text { reference }\end{array}$ & Parcel & $\tau_{\max } / \mathbf{S}_{\mathbf{u}}$ & $\mathbf{N}$ & $\begin{array}{c}\text { Maximum } \\
\text { measured } \\
\gamma_{\max }(\%) \\
\end{array}$ & $\begin{array}{c}\text { Maximum } \\
\text { predicted } \\
\gamma_{\max }(\%) \\
\end{array}$ & $\begin{array}{c}\text { Predicted } \\
\mathbf{N}_{\text {eq }}\end{array}$ \\
\hline \multirow{2}{*}{ StCns1 } & 1 & 0.75 & 50 & & \multirow{2}{*}{21} & \multirow{2}{*}{24} \\
\hline & 2 & 0.86 & 15 & 14.0 & & \\
\hline \multirow{2}{*}{ StCns2 } & 1 & 0.80 & 15 & 9.9 & \multirow{2}{*}{12} & \multirow{2}{*}{25} \\
\hline & 2 & 0.70 & 50 & & & \\
\hline
\end{tabular}


(a)

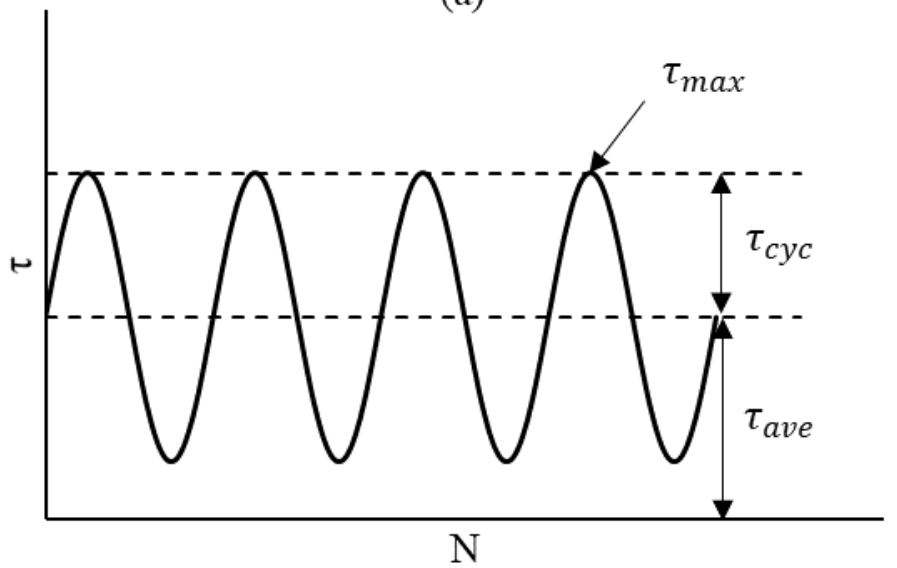

(b)

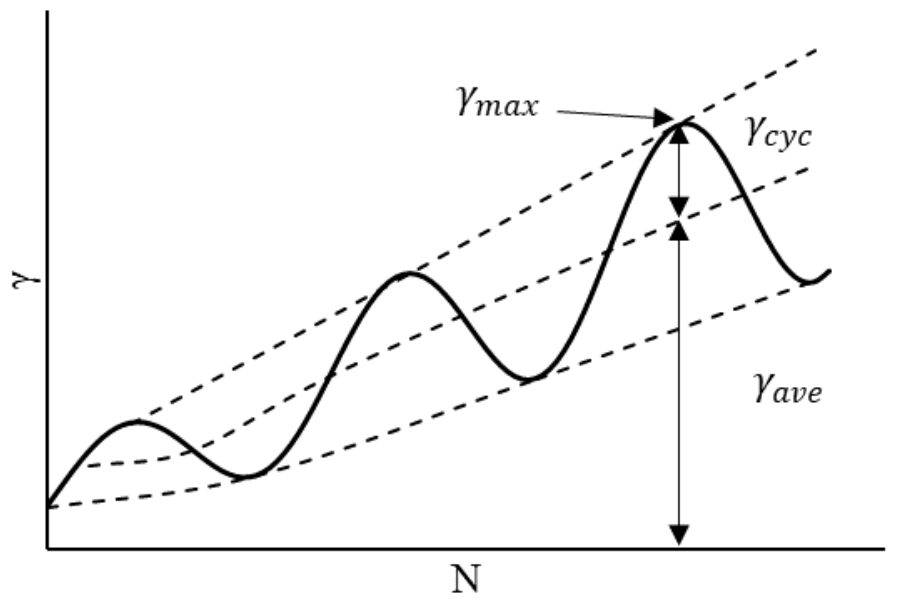

Figure 1 (a) Shear stress and (b) shear strain components in stress-controlled cyclic DSS tests 

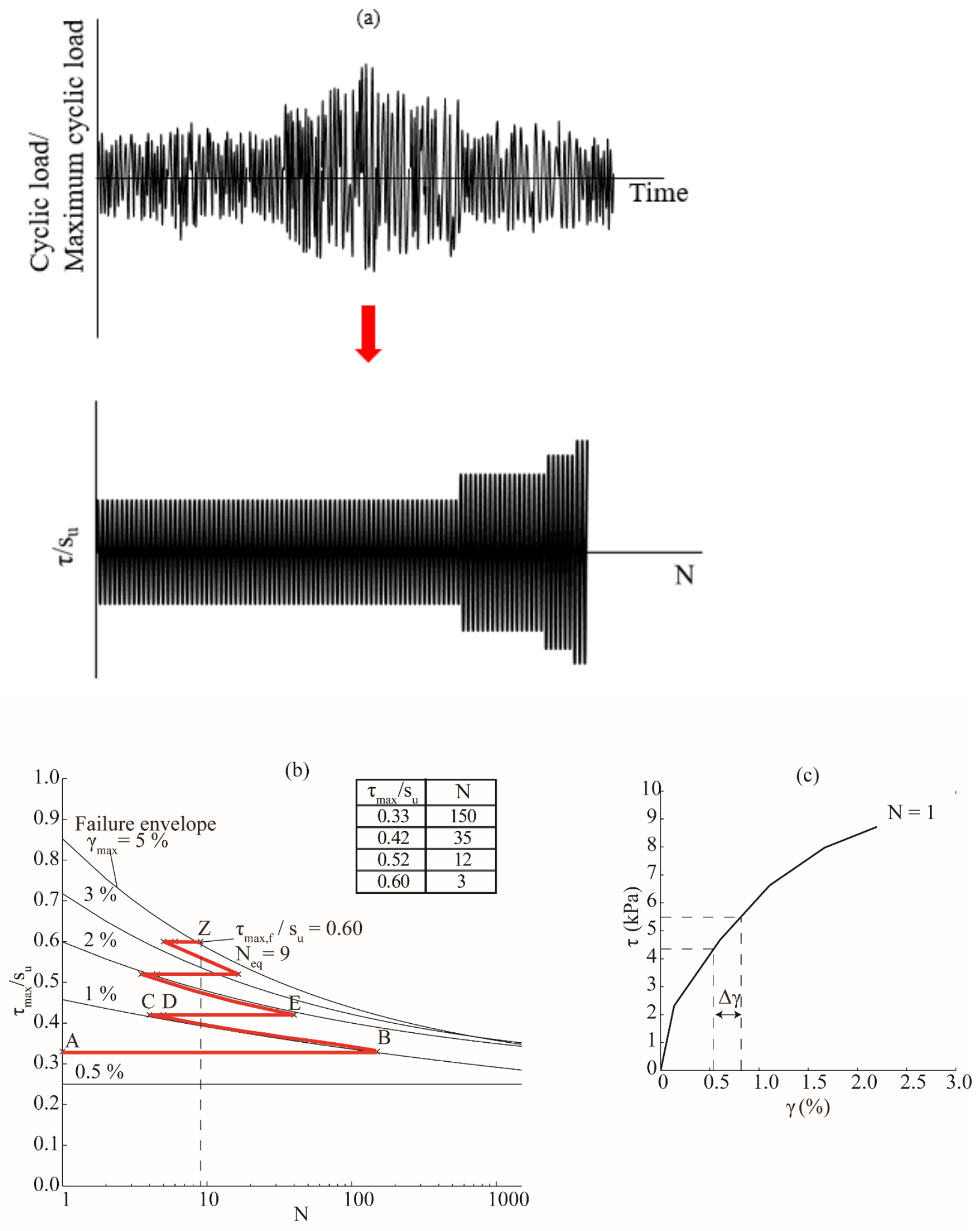

Figure 2 (a) Irregular cyclic load history transformed into parcels of uniform cyclic shear stress (b) the accumulation procedure for the cyclic stress history on a contour diagram of $\gamma_{\max }$ and (c) assessment of $\Delta \gamma$ due to stress increment between parcels from stress-strain response at $\mathrm{N}=1$ 
(a)

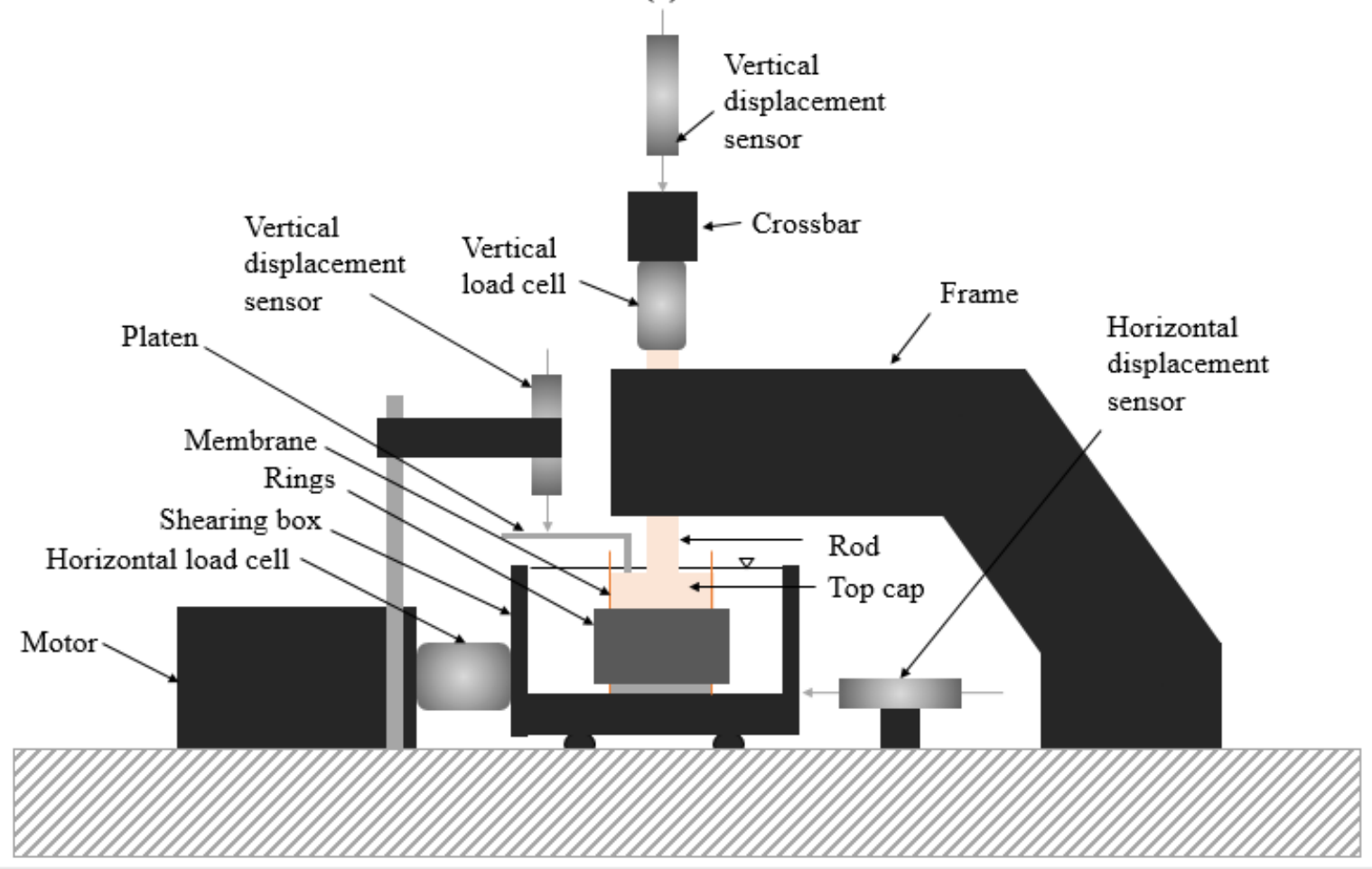

(b)

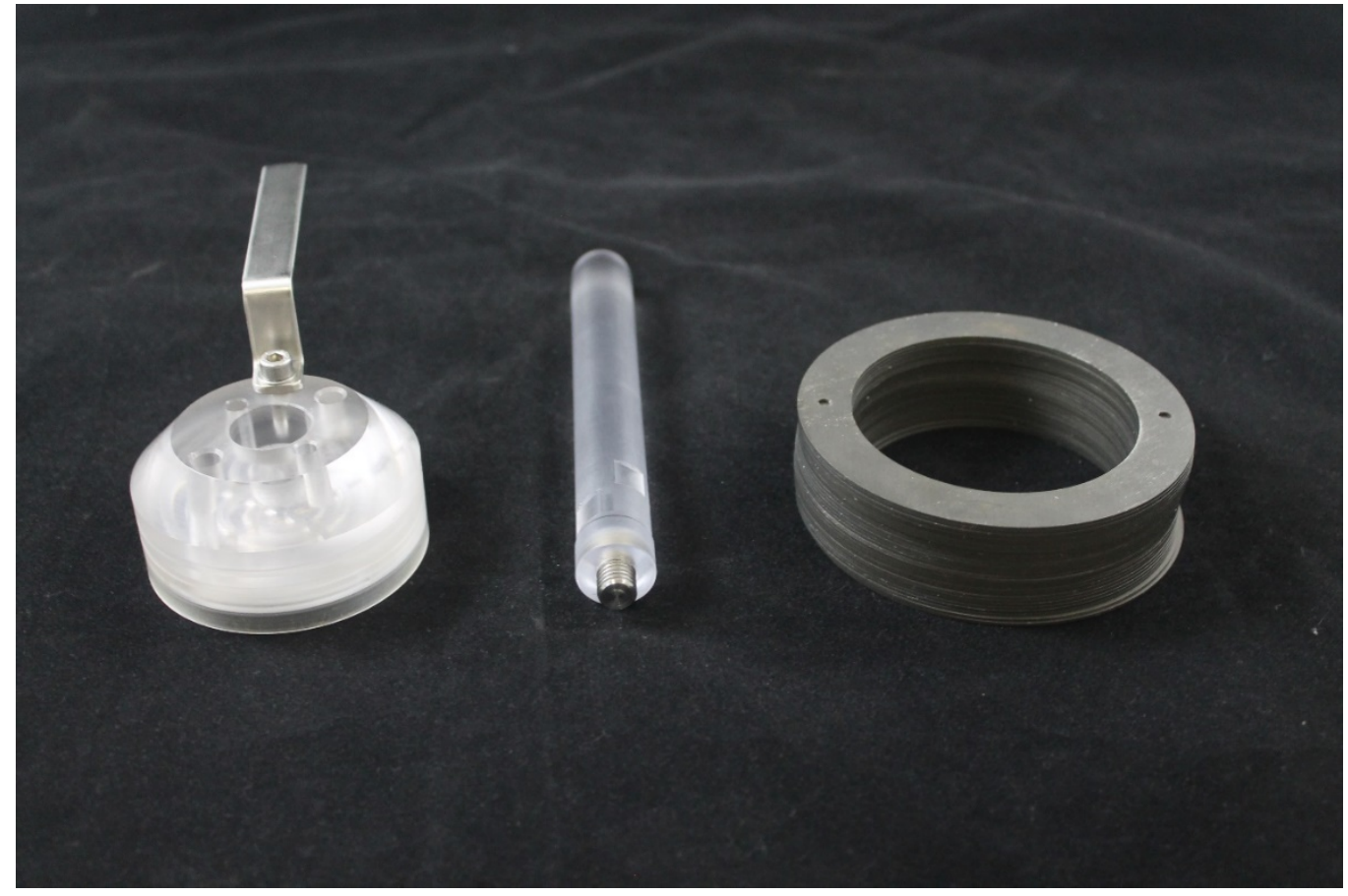

Figure 3 Geocomp DSS apparatus: (a) schematic representation, and (b) polycarbonate top cap and rod and Teflon coated stacked rings 

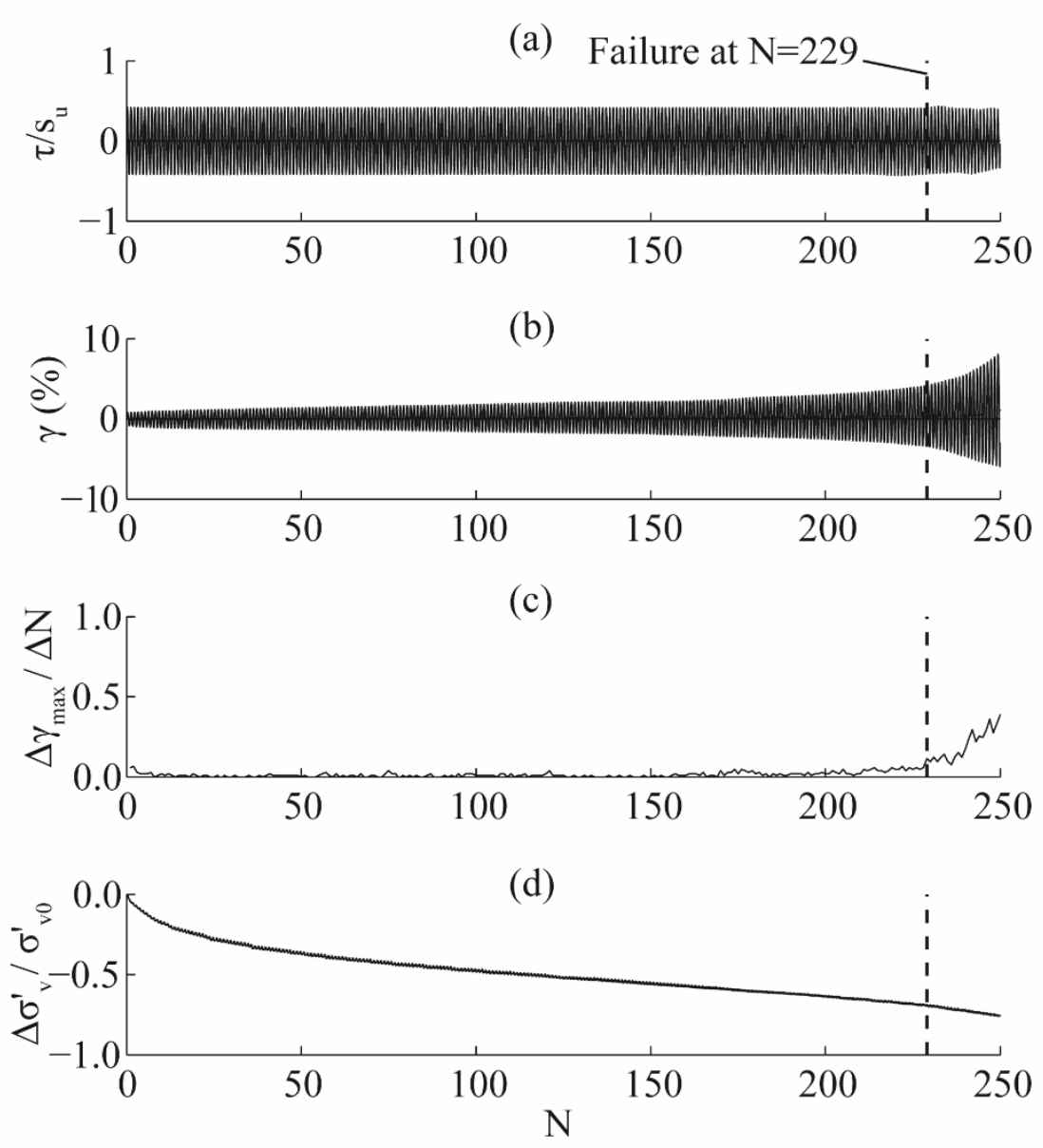

(e)

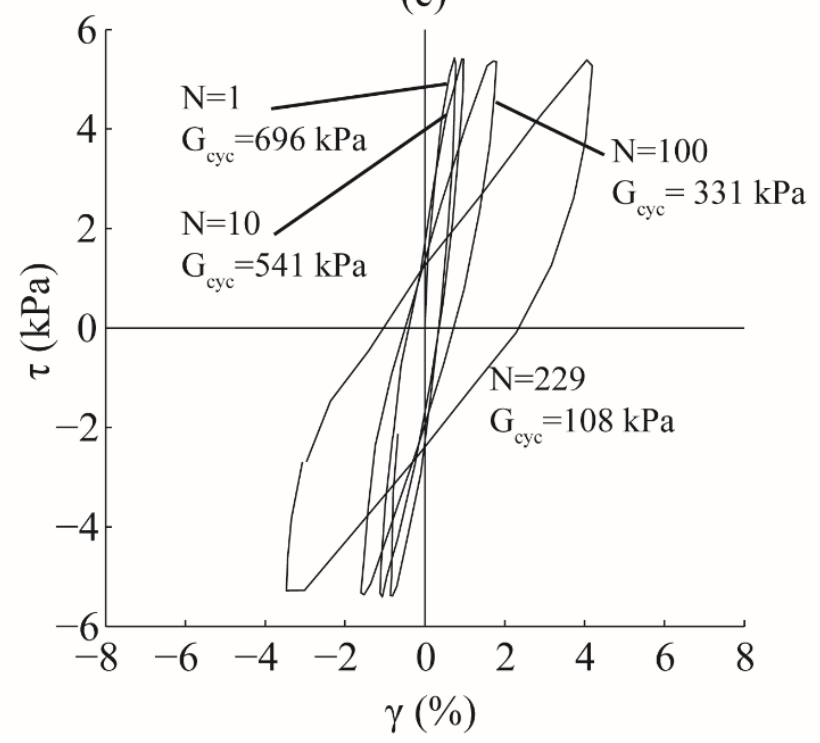

Figure 4 Typical results from a symmetrical cyclic DSS tests under $\tau_{\max } / \mathrm{s}_{u}=0.41$ [Cs3]: a) input shear stress and measured response during cycling and (b) stress-strain response at cycle numbers, $N=1$, 10,00 and 229 
(a)

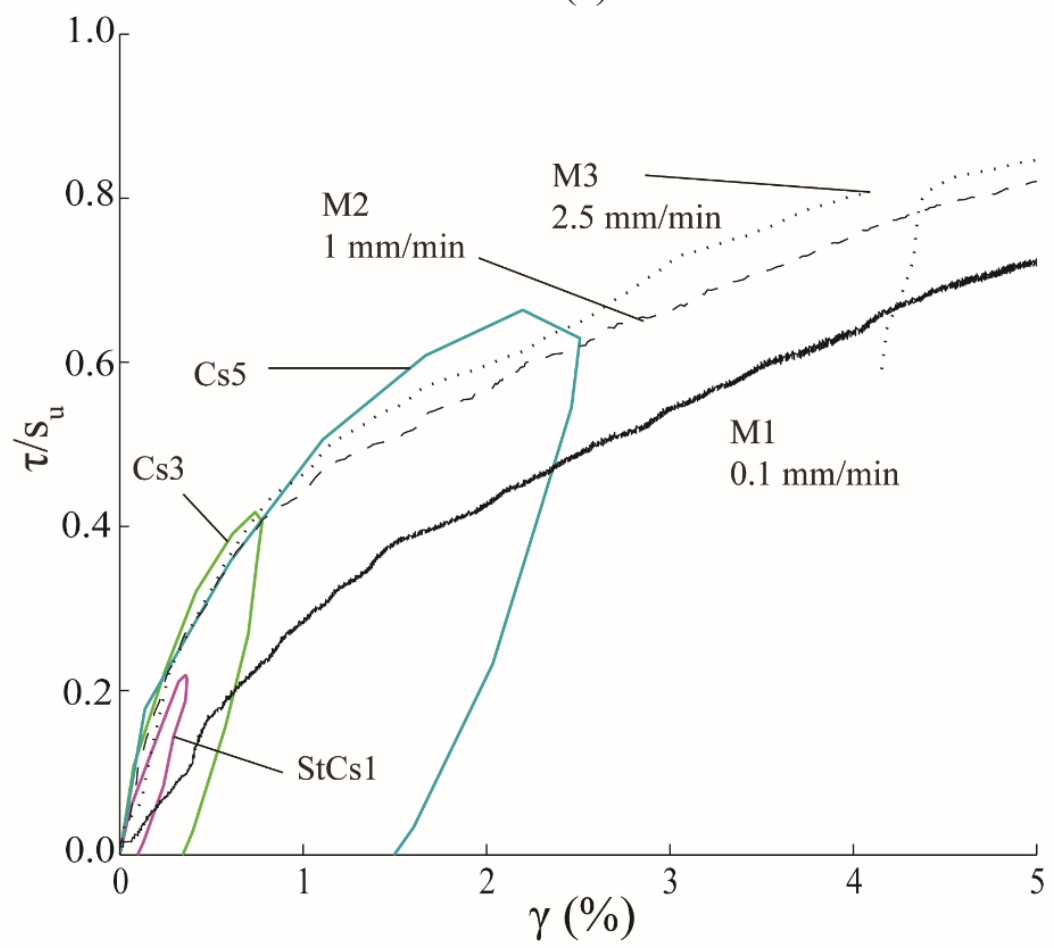

(b)

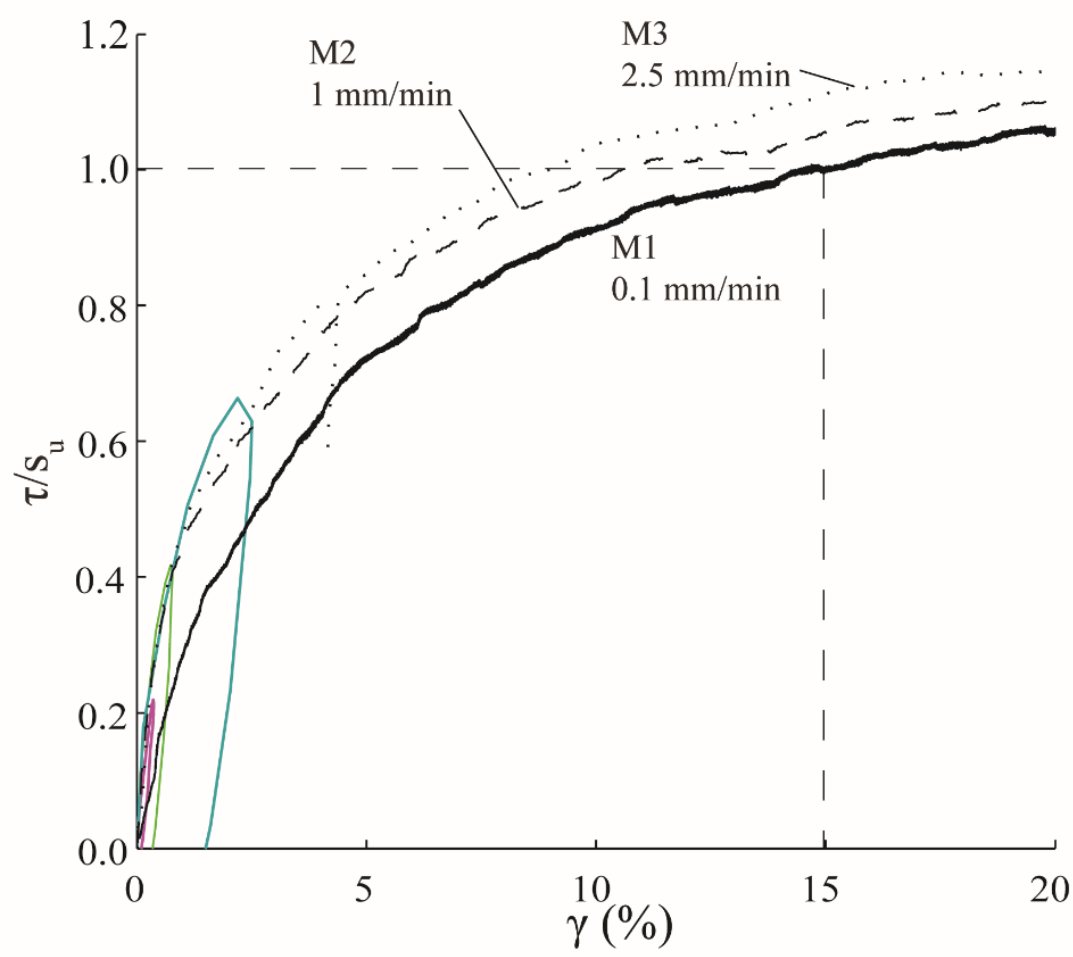

Figure 5 Stress-strain response at $\mathrm{N}=1$ of symmetrical cyclic DSS tests and in monotonic DSS tests performed at $0.1 \mathrm{~mm} / \mathrm{min}, 1 \mathrm{~mm} / \mathrm{min}$ and $2.5 \mathrm{~mm} / \mathrm{min}$ for a) $\gamma: 0-5 \%$ and b) $\gamma 0-20 \%$ 


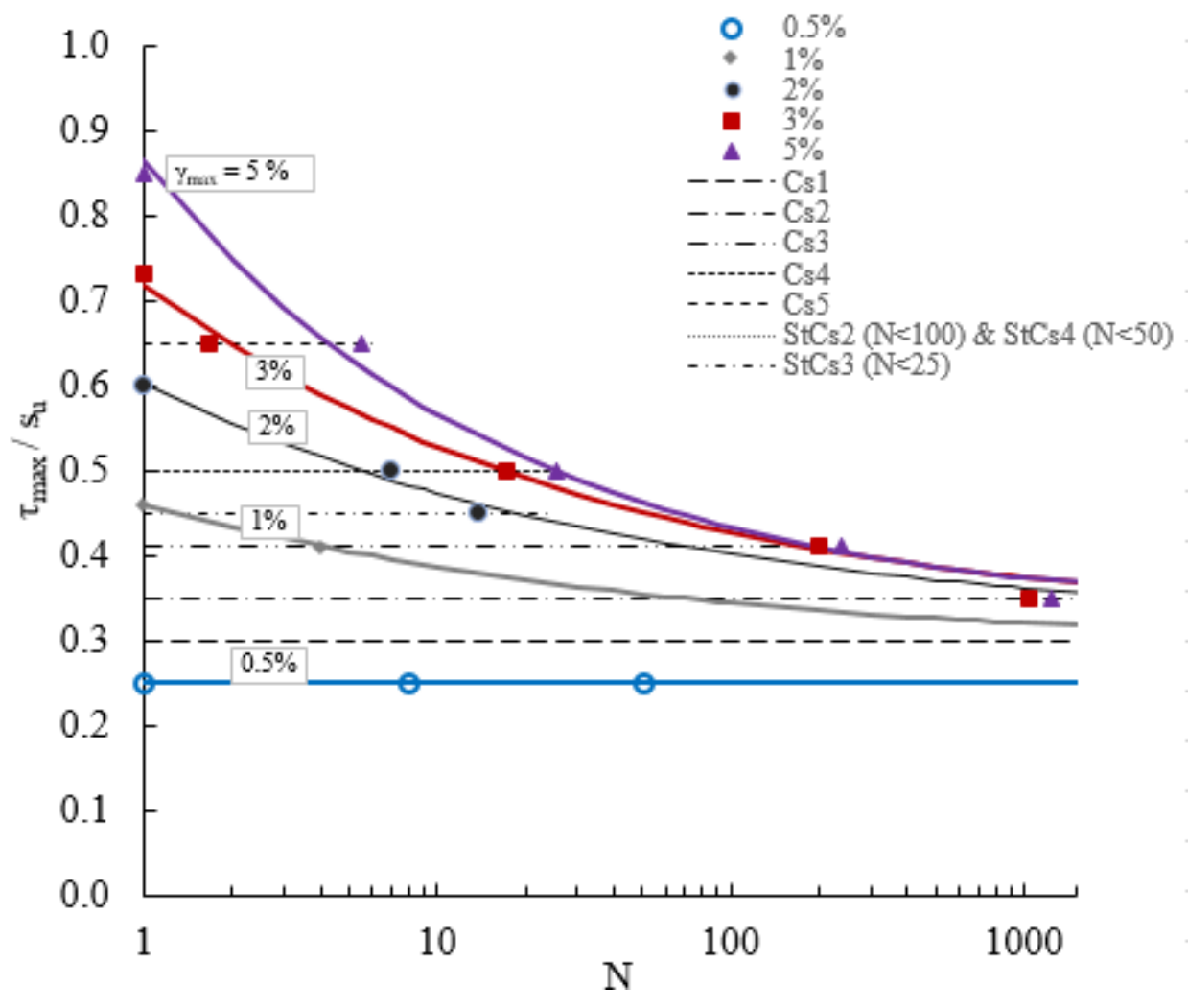

Figure 6 Contour diagram of $\gamma_{\max }$ derived from symmetrical cyclic DSS tests with CSR $=\infty$ 


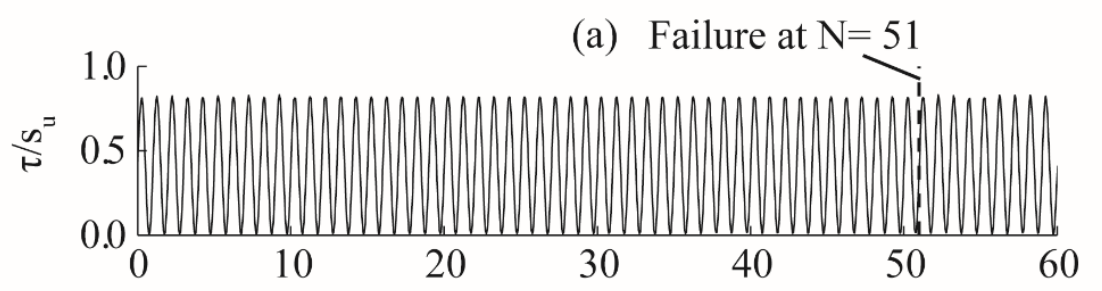

(b)

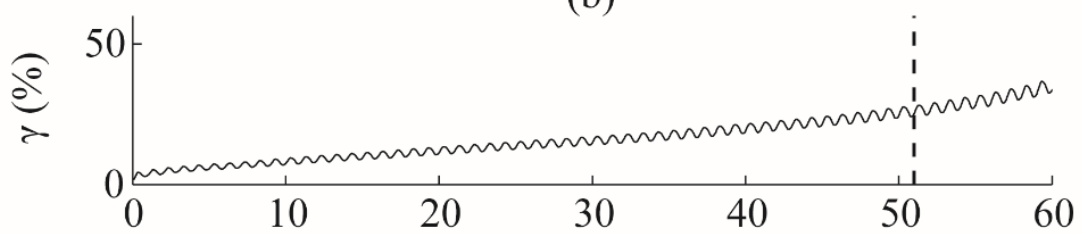

(c)

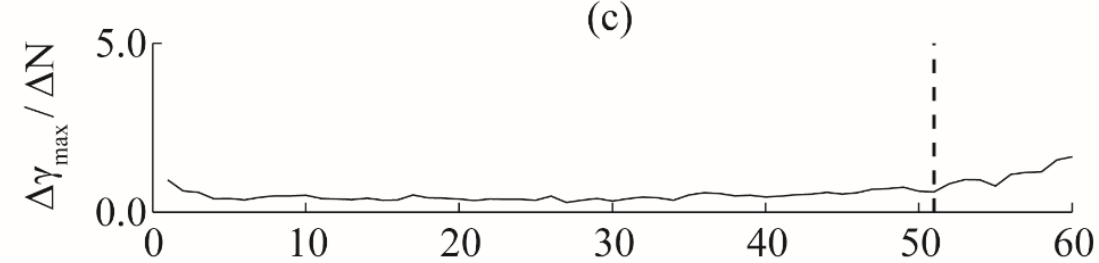

(d)

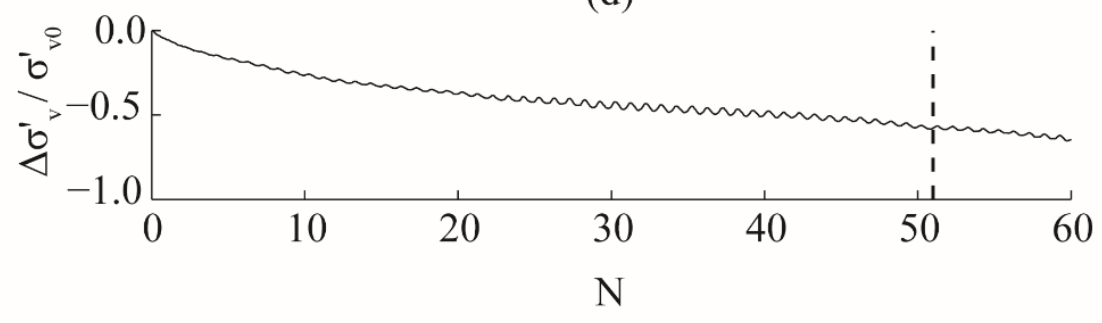

(e)

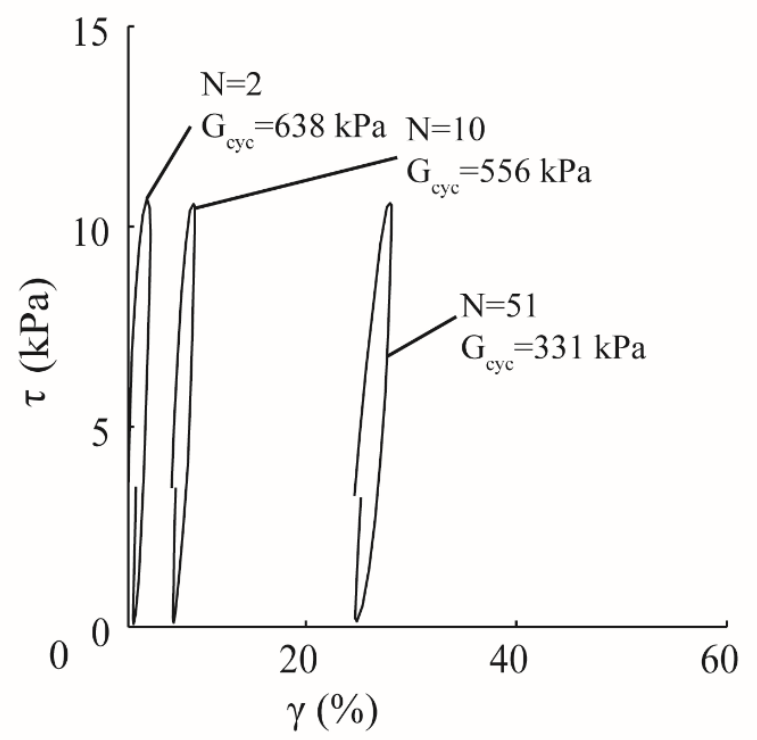

Figure 7 Typical results from non-symmetrical cyclic DSS tests under $\tau_{\text {ave }} / \mathrm{s}_{u}=0.41$ and CSR $=1$ [Cns4]: a) input shear stress and measured response during cycling and (b) stress-strain response at cycle numbers, $\mathrm{N}=2,10$ and 51 
(a)

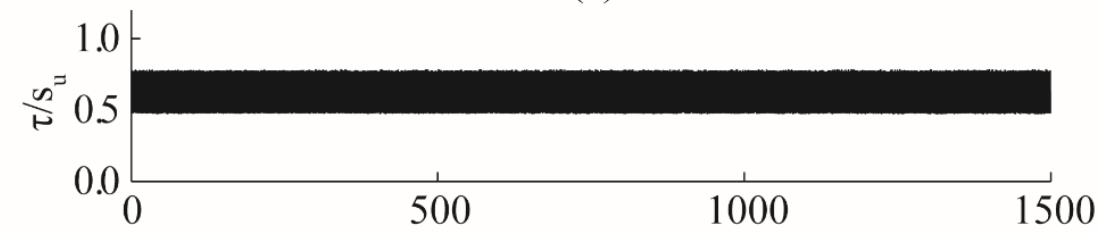

(b)

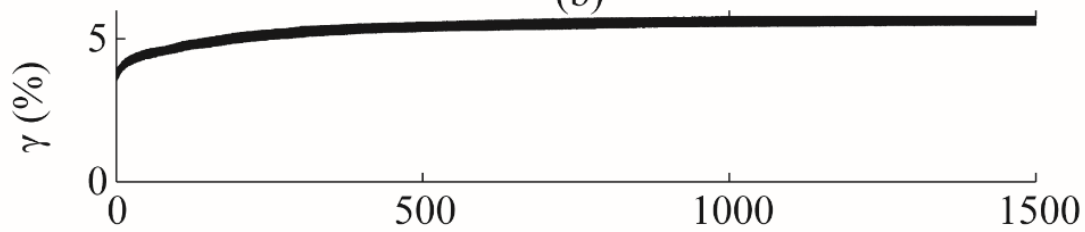

(c)

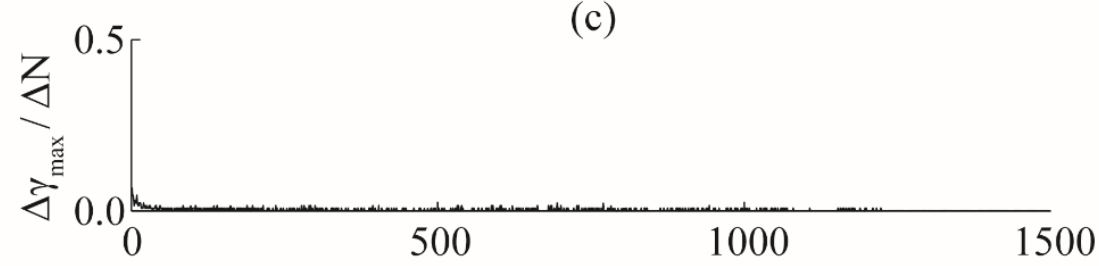

(d)

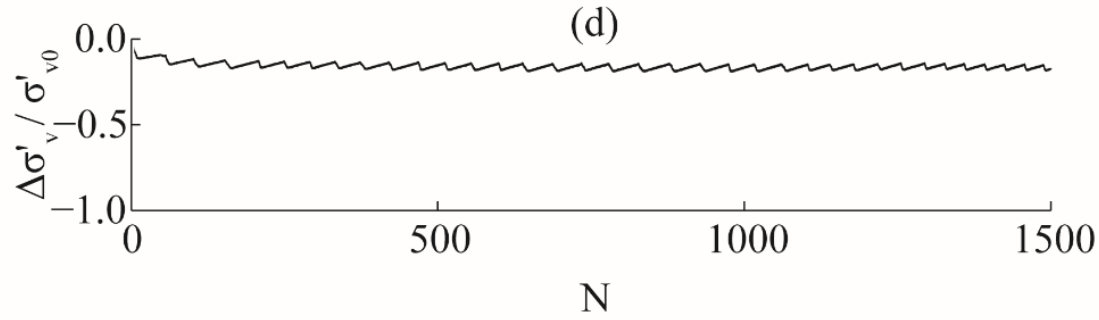

(e)

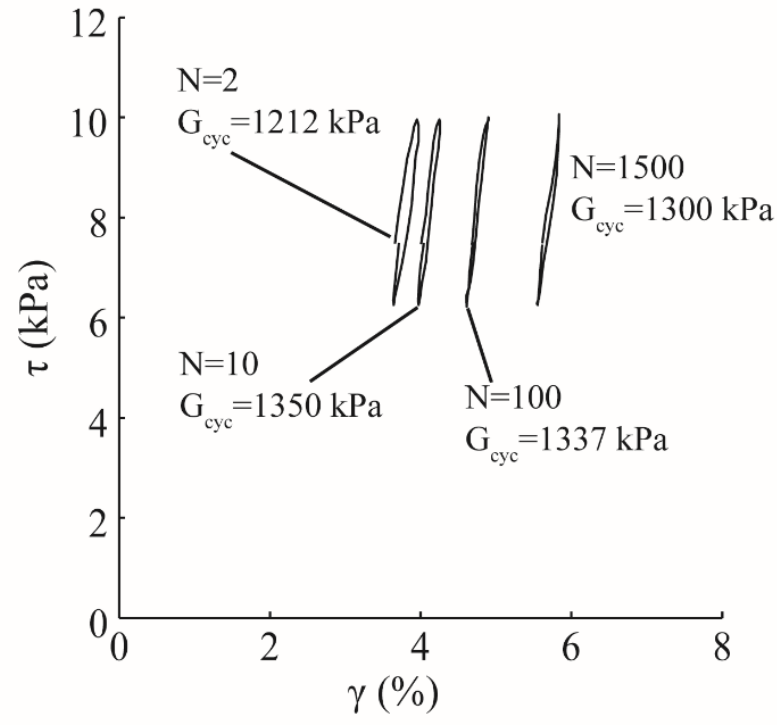

Figure 8 Typical results from non-symmetrical cyclic DSS tests under $\tau_{\text {ave }} / \mathrm{s}_{u}=0.62$ and CSR $=0.26$ [Cns8]: a) input shear stress and measured response during cycling and (b) stress-strain response at cycle numbers, $\mathrm{N}=2,10,100$ and 1500 


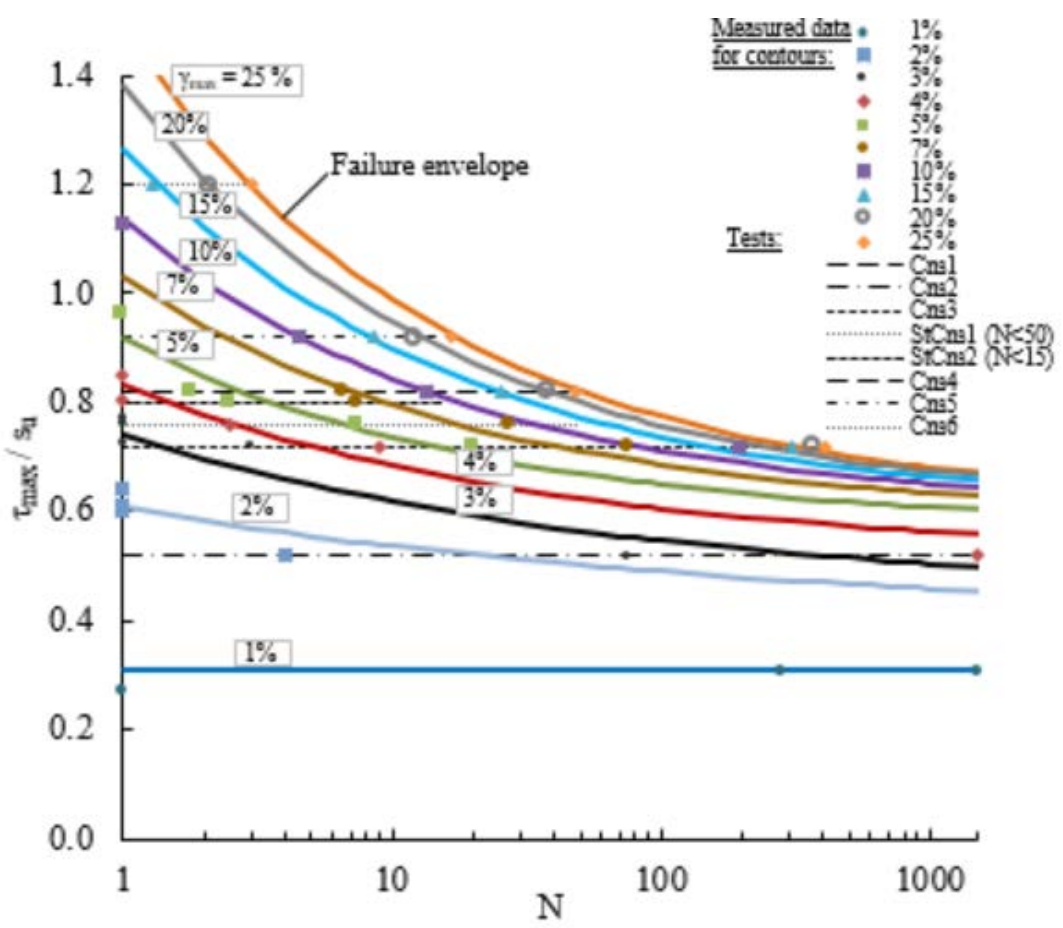

Figure 9 Contour diagram of $\gamma_{\max }$ derived from non-symmetrical cyclic DSS tests with CSR=1 

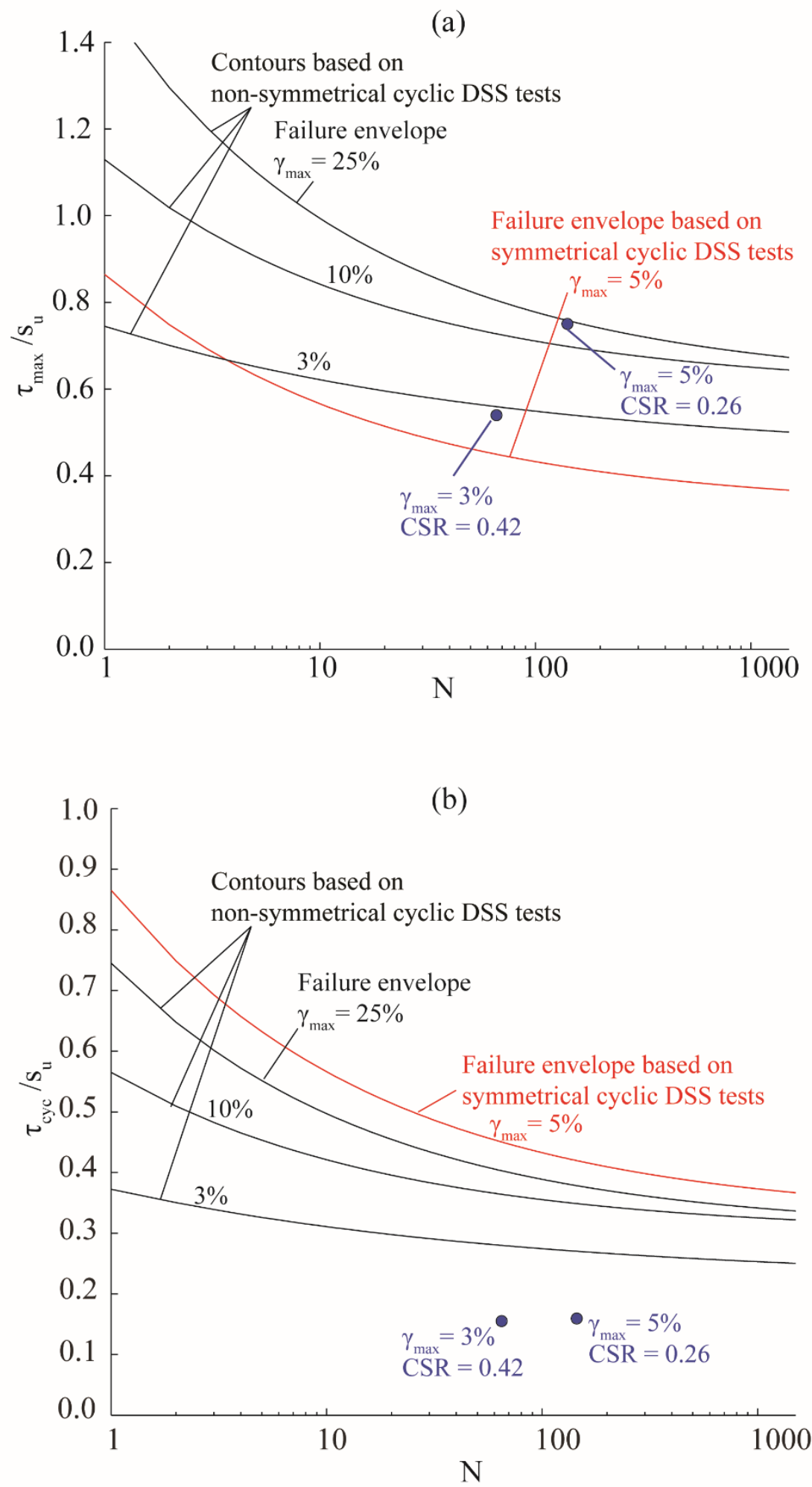

Figure 10 Comparison of contour diagrams from symmetrical tests and non-symmetrical tests (with CSR $=1$ ) as a function of a) $\tau_{\max } / s_{u}$ and $\left.b\right) \tau_{c y c} / s_{u}$ 

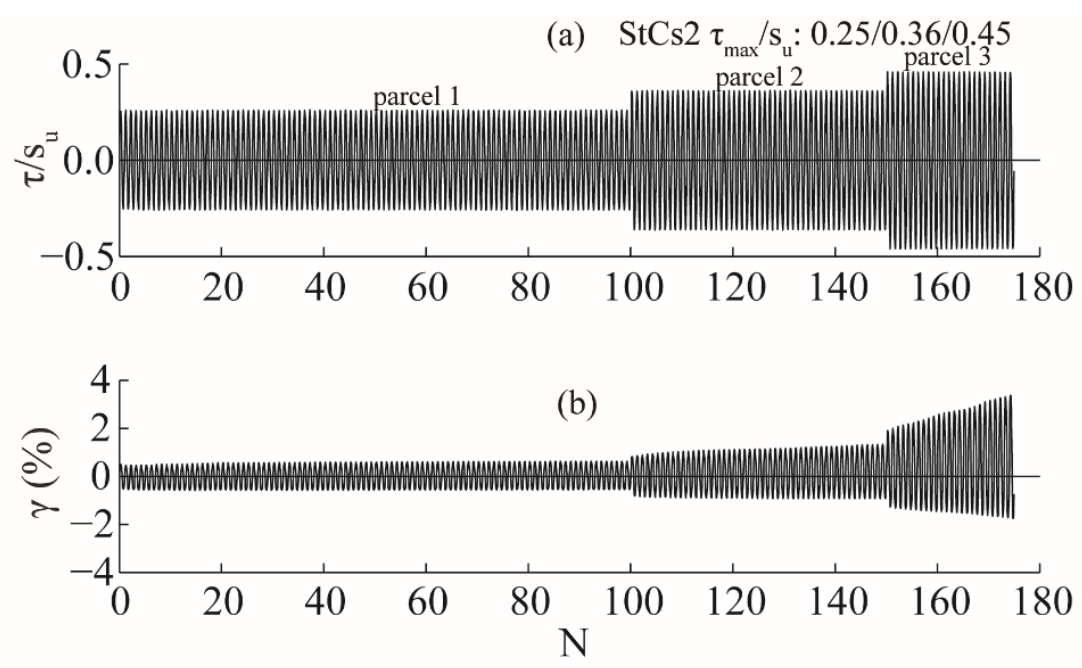

Figure 11 Results from staged symmetrical cyclic DSS tests under $\tau_{\max } / \mathrm{s}_{u}=0.25,0.36$ and 0.45 [StCs2]
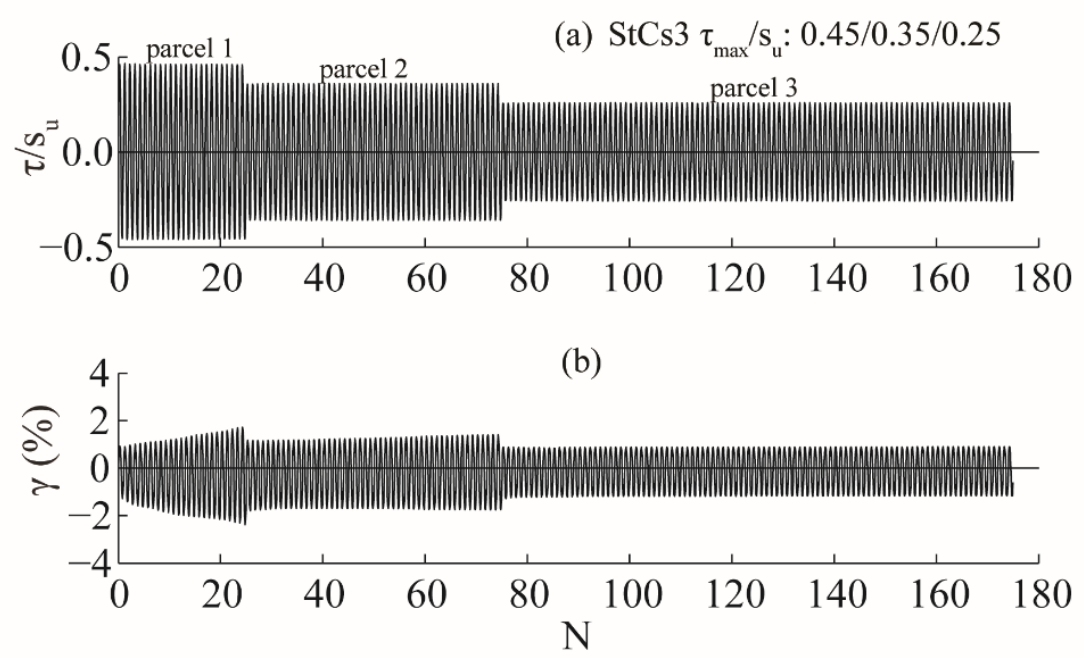

Figure 12 Results from staged symmetrical cyclic DSS tests under $\tau_{\max } / \mathrm{s}_{u}=0.45,0.35$ and 0.25 [StCs3] 
(a) StCs4 $\tau_{\max } / \mathrm{s}_{\mathrm{u}}: 0.25 / 0.35 / 0.45 / 0.35 / 0.25$

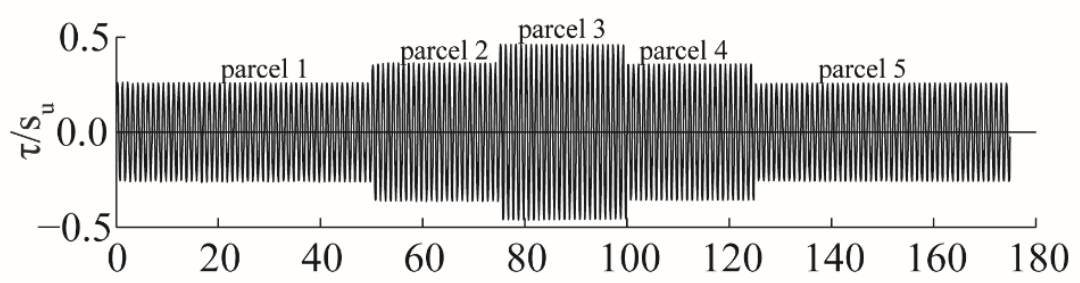

(b)

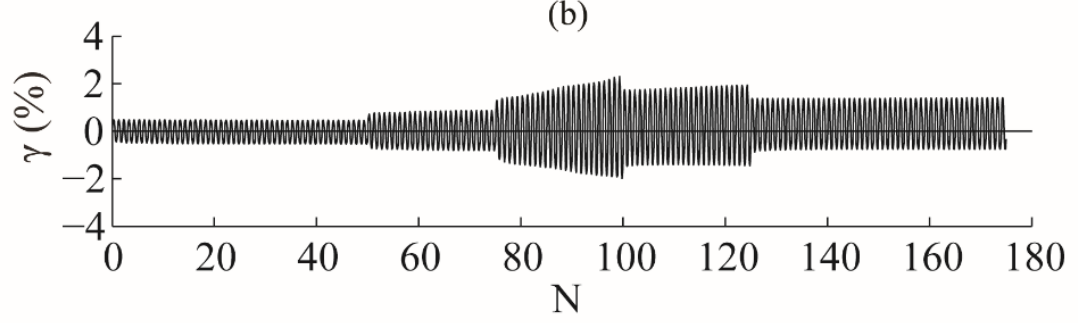

Figure 13 Results from staged symmetrical cyclic DSS tests under $\tau_{\max } / \mathrm{s}_{\mathrm{u}}=0.25,0.35,0.45,0.35$ and $0.25[$ StCs4]

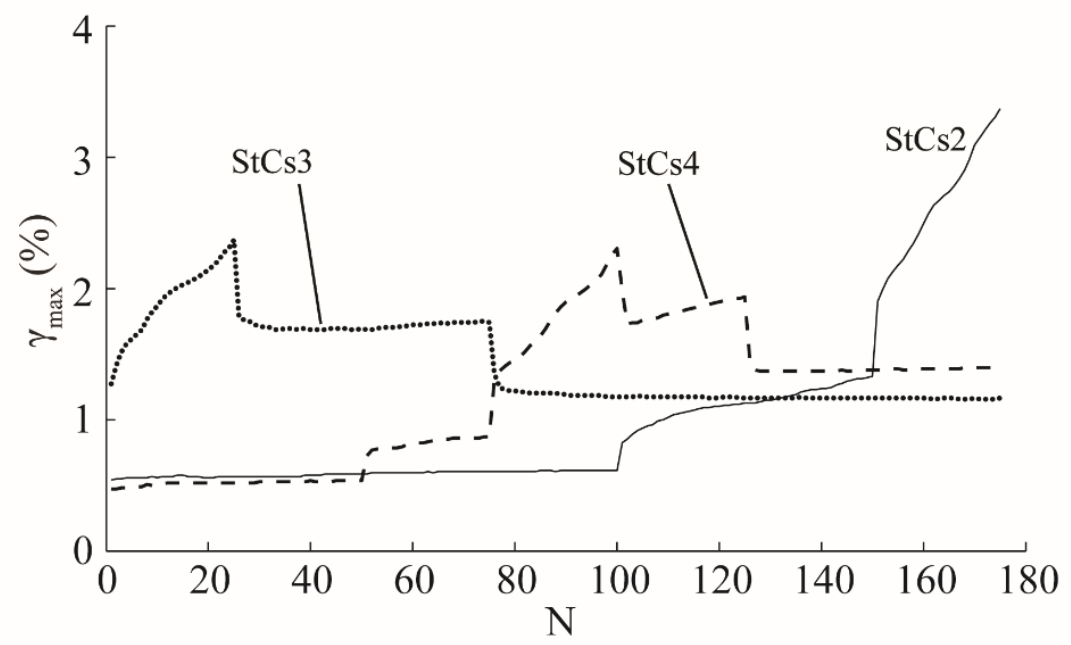

Figure 14 Comparison of $\gamma_{\max }$ from staged symmetrical cyclic DSS tests 
(a)

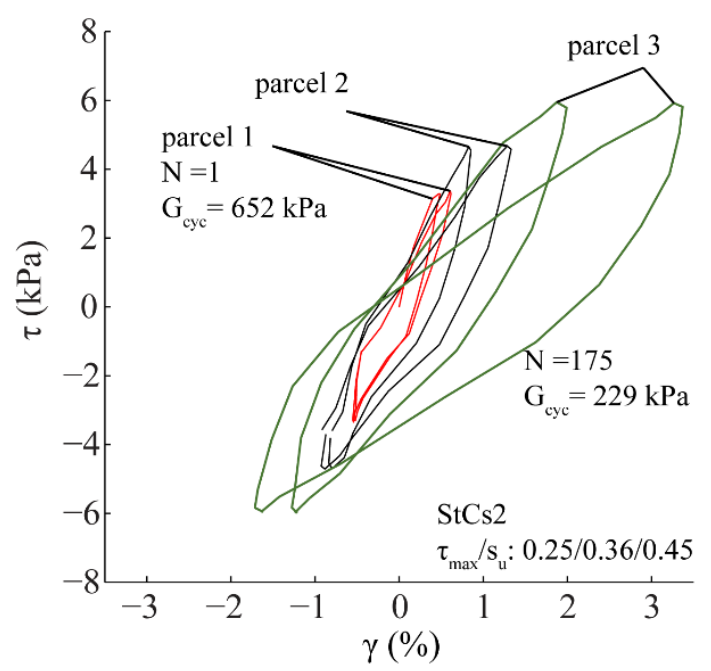

(b)

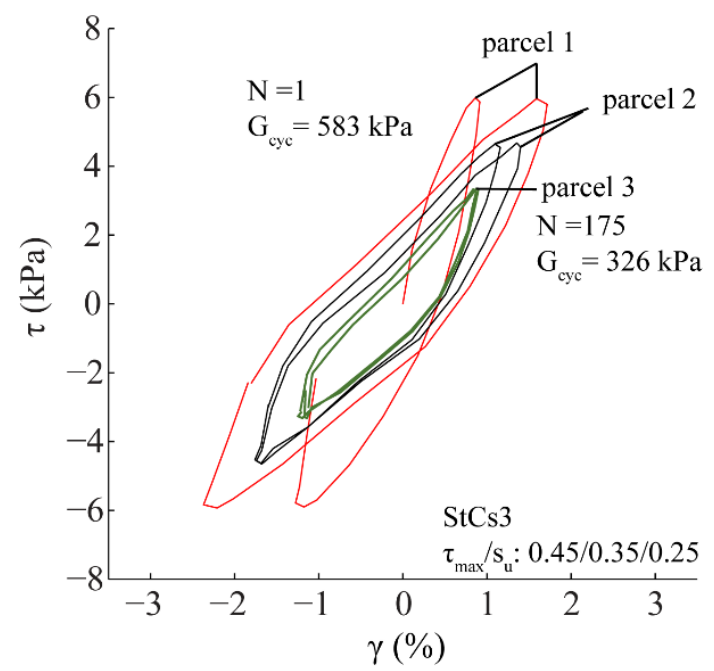

(c)

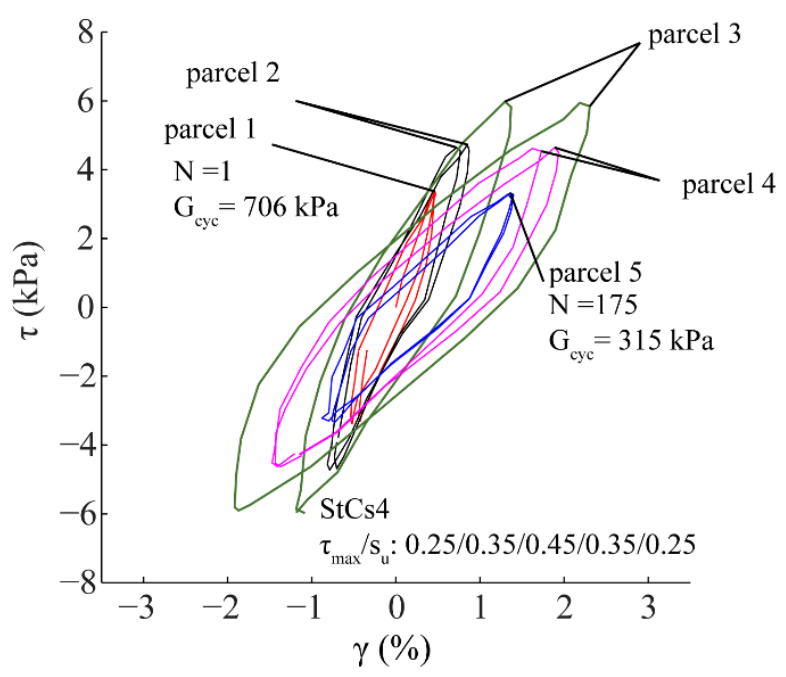

Figure 15 Stress-strain loops at the beginning and at the end of each parcel of staged symmetrical cyclic DSS tests under: (a) $\tau_{\max } / \mathrm{s}_{\mathrm{u}}=0.25,0.36$ and 0.45 [StCs2] (b) $\tau_{\max } / \mathrm{s}_{\mathrm{u}}=0.45,0.35$ and 0.25 [StCs3] and (c) $\tau_{\max } / s_{u}=0.25,0.35,0.45,0.35$ and 0.25 [StCs4] 


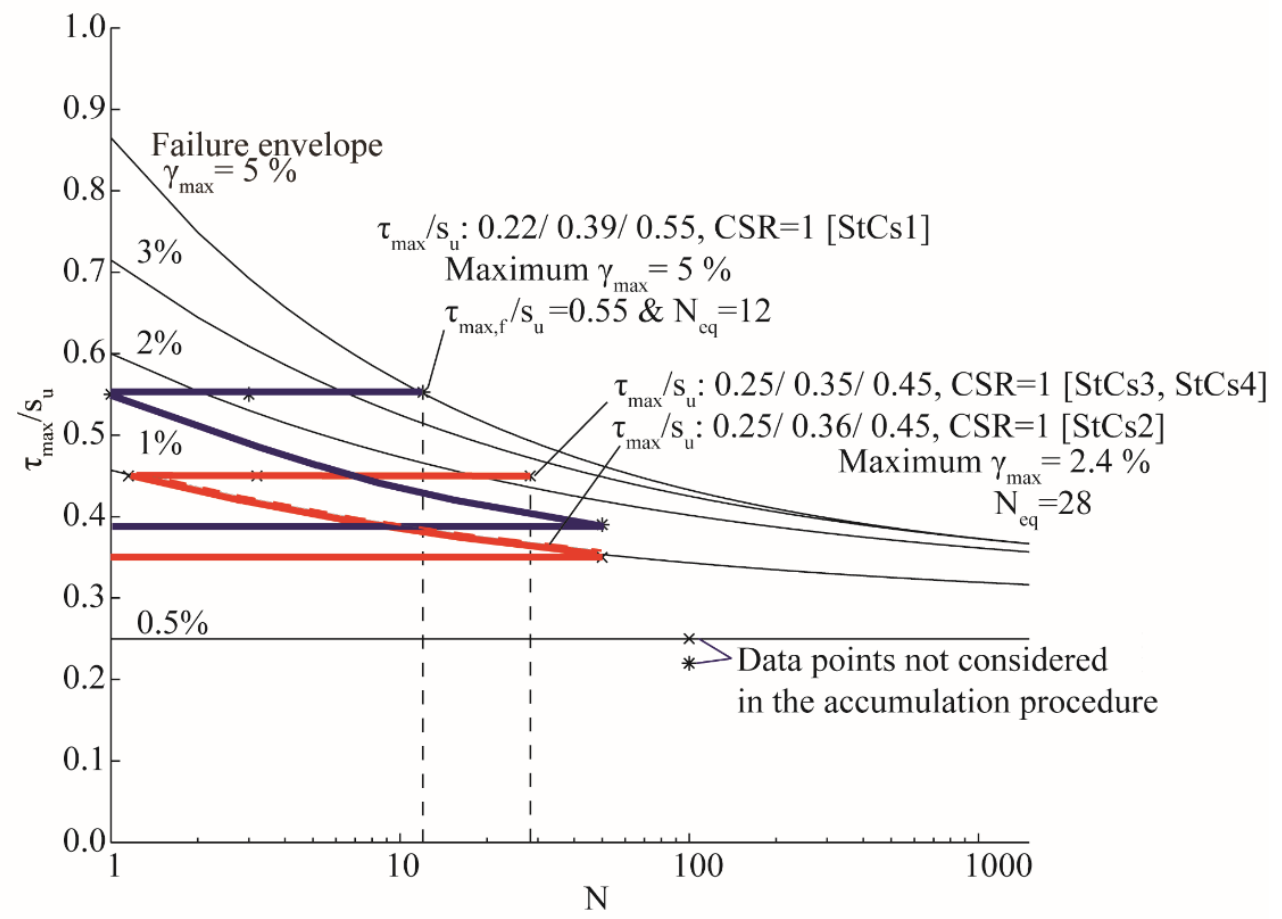

Figure 16 Accumulation procedure for the staged symmetrical cyclic DSS tests

(a) StCns 1

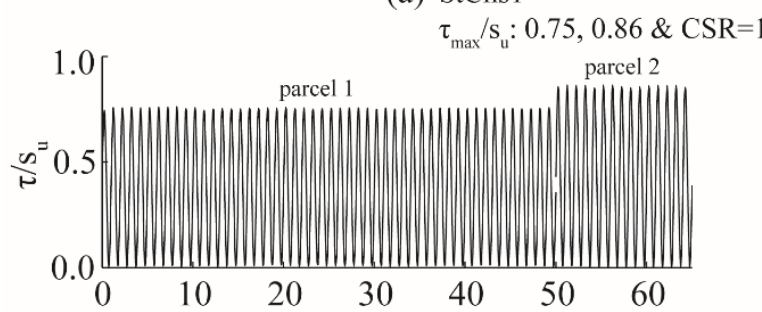

(b) StCns2

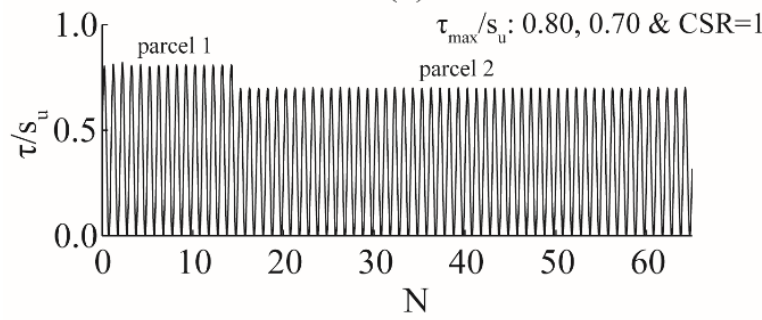

(c)

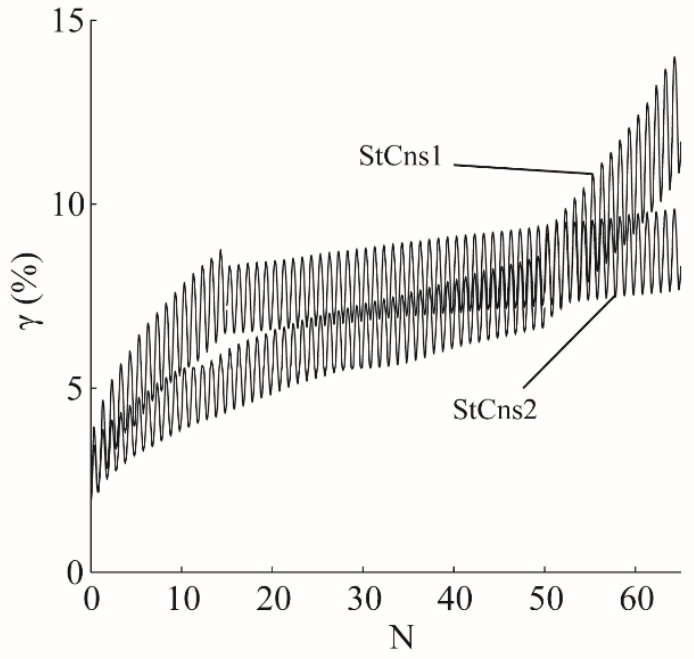

Figure 17 Results from staged non-symmetrical cyclic DSS tests under $\tau_{\max } / \mathrm{s}_{\mathrm{u}}=0.75 / 0.86$ and $\tau_{\max } / s_{u}=0.80 / 0.70:$ a) $\tau / s_{u}$, and (b) $\gamma$ 
(a)

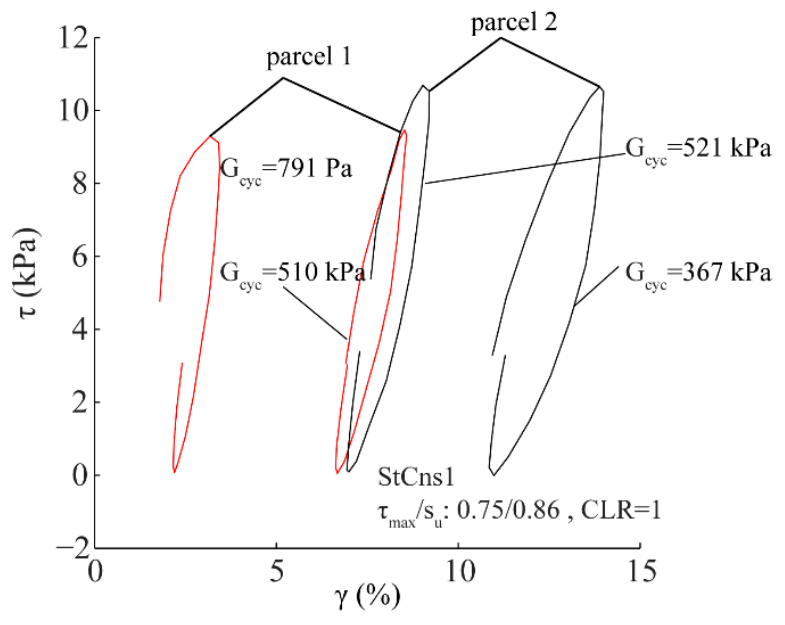

(b)

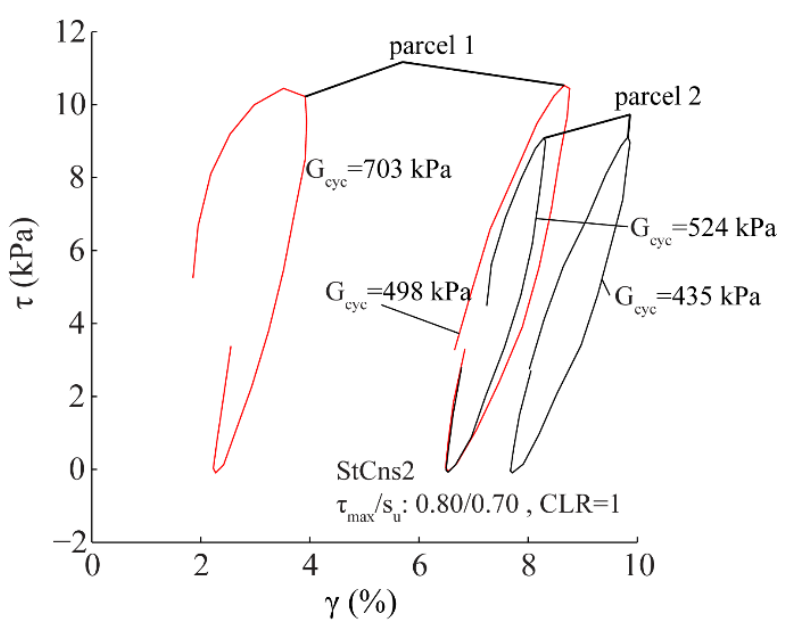

Figure 18 Stress-strain loops at the beginning and at the end of each parcel of the staged nonsymmetrical cyclic DSS tests under: (a) $\tau_{\max } / \mathrm{s}_{u}=0.75 / 0.86[\mathrm{StCns} 1]$ and (b) $\tau_{\max } / \mathrm{s}_{u}=0.80 / 0.70$ [StCns2] 


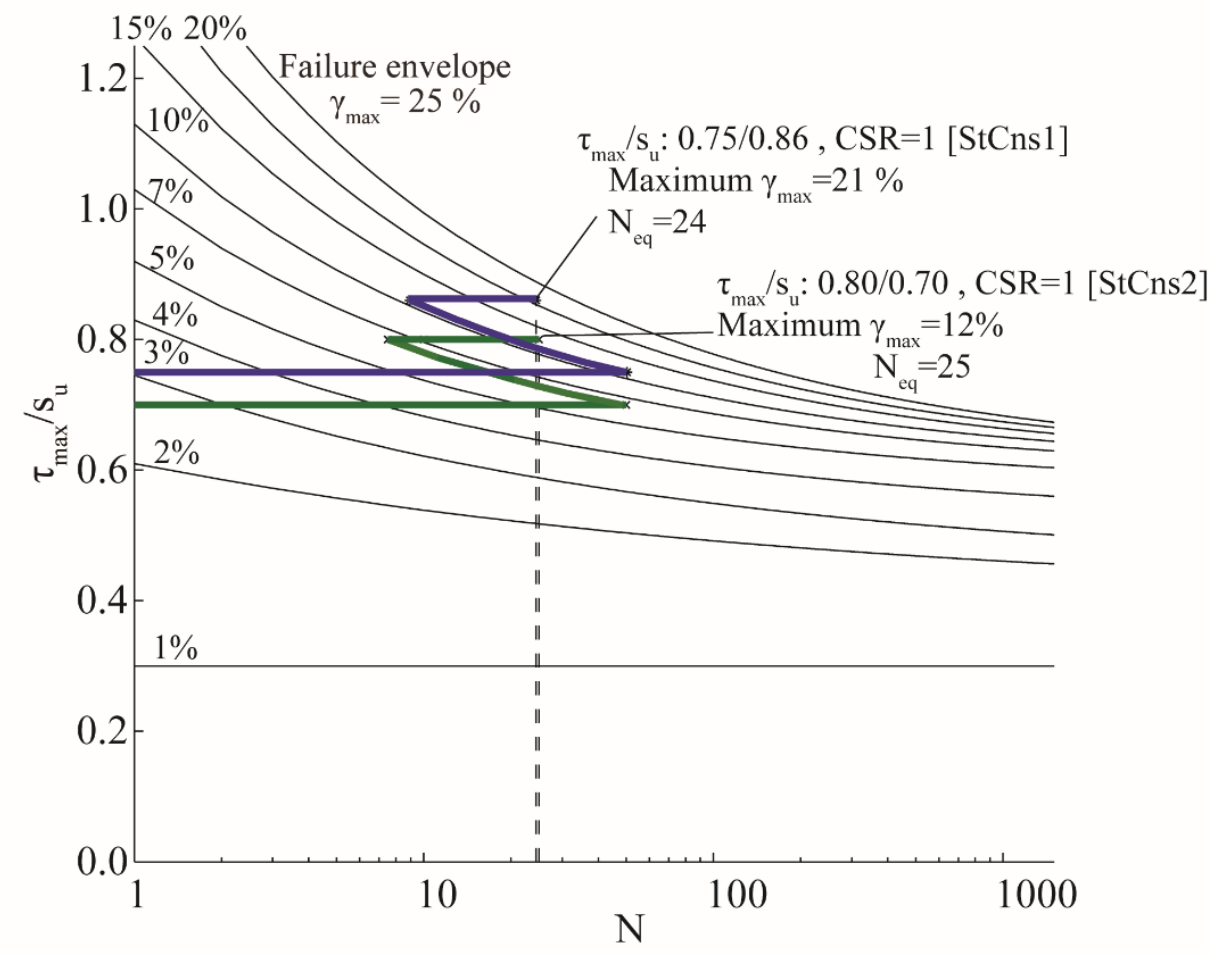

Figure 19 Accumulation procedure for the staged non-symmetrical cyclic DSS tests 